\title{
Generation and analysis of stage-fall-discharge laws from coupled hydrological-hydraulic river network model integrating sparse multi-satellite data
}

\author{
T. Malou ${ }^{1,2,3}$, P.-A. Garambois ${ }^{4}$, A. Paris ${ }^{5}$, J. Monnier ${ }^{1,2}$, K. Larnier ${ }^{6}$ \\ ${ }^{1}$ INSA Toulouse, France \\ ${ }^{2}$ Institut de Mathématiques de Toulouse, France \\ ${ }^{3}$ Collecte Localisation Satellite (CLS), Toulouse, France \\ ${ }^{4}$ INRAE (Irstea), Aix Marseille Univ, RECOVER, Aix-en-Provence, France \\ ${ }^{5}$ Ocean Next, Toulouse, France \\ ${ }^{6}$ CS corporation, Business Unit Espace, Toulouse, France
}

September 27, 2021

\section{Contents}

1 Introduction 3

2 Flow models and observables 5

2.1 River network flow model . . . . . . . . . . . . . . . . . . . . . . . . 6

$10 \quad 2.2$ The computational inverse method . . . . . . . . . . . . . . . . . . . . . . 6

2.3 Stage-Fall-Discharge laws . . . . . . . . . . . . . . . . . . . . . . . . . 7

2.3.1 From flow resistance to SFD . . . . . . . . . . . . . . . . . . . . 7

2.3.2 Computation of SFD laws coefficients . . . . . . . . . . . . . . . . . 8

3 Study zone and calibrated river network model 9

3.1 Study area and multi-satellite data . . . . . . . . . . . . . . . . . . . . . . . . 9

3.2 Construction of the hydrodynamic model . . . . . . . . . . . . . . . . . . . . . . 11

3.3 Space-time simulation of hydraulic quantities with the river network model . . . . . . . . . . 13

3.3.1 Hydraulic quantities from the calibrated river network model . . . . . . . . . . . . . . 14

3.3.2 Slope computations . . . . . . . . . . . . . . . . . . . . 17

3.3.3 Extrapolation of the discharge . . . . . . . . . . . . . . . . . . . . 18

4 SFD calibration and analysis 19

4.1 Numerical experiment design ... . . . . . . . . . . . . . . . . . . . . . . . 19

4.1.1 SFD and SD variants considered . . . . . . . . . . . . . . . . . . 19

4.1.2 Selection of altimetric virtual stations for SFD estimation . . . . . . . . . . . . . . 20

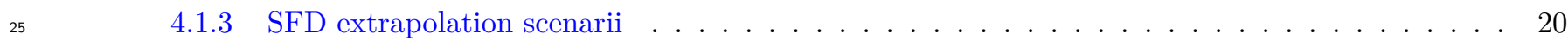

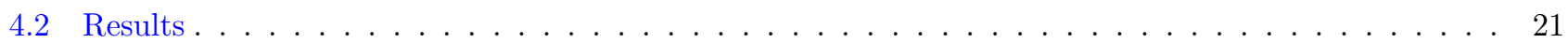


4.2.1 Performance of discharge SFD . . . . . . . . . . . . . . . . . . . . 21

4.2.2 Analysis of the SFD coefficients . . . . . . . . . . . . . . . . . . . 22

5 Discussions 26

5.1 AMHG analysis of Negro-Branco SD coefficients . . . . . . . . . . . . . . . . . . . 27

5.2 Influence of hydraulic controls and water masks on SFD . . . . . . . . . . . . . . . . . 27

6 Conclusion

A Performance evaluation metrics

B Performance evaluation on the stations

D Usual parameterizations of flow resistance

\title{
References
}

Highlights

- Method for hydraulic model derived stage fall discharge

- Spatially distributed variational calibration of a hydraulic network model

- Multi-mission altimetry data assimilation

- Stage-fall-discharge laws amenable to satellite altimetry

\begin{abstract}
Current and forthcoming altimetry satellites provide increasing hydraulic visibility of river surface variabilities. However, due to unobservable river bathymetry and friction, as well as the sampling and quality of remote sensing data, discharge estimation remains a challenging problem. This paper proposes a new rigorous methodology to estimate stage-fall-discharge laws at any point of a hydrographic network including backwater affected reaches. This methodology is adapted to operational estimation of discharge from multi-mission satellite altimetry data. The cornerstone of the method is to take advantage of meaningful hydraulic signatures, including water surface slopes, simulated by a river network model optimally combined with multi-satellite noisy observations. This optimal combination of heterogeneous multi-source data with a river network model is achieved through variational data assimilation performed using the DassFlow-HiVDI hydraulic model inflowed by MGB regional hydrological model. It is newly applied to the large and complex Negro-Branco River network in the Amazon basin. An effective model is obtained by variational calibration using Jason-3 and Sentinel-3A and -3B altimetry observations between February 2016 and May 2019. A fairly good fit bellow $1 m$ for $80 \%$ of the altimetric observations is obtained. Using this hydrodynamic model as a fine spatio-temporal extrapolator of hydraulic quantities, and in particular of multi-scale water surface slope signatures, the parameters of a general SFD law, as well as the uncertainties estimations, can be constrained at any location within the river network domain using a Bayesian optimization method. This methodology is tested over 4 virtual stations representing various hydraulic complexities. Accurate discharge estimates and meaningful SFD parameters are obtained compared to those of the reference low Froude model at these locations. Analyses are also performed on a reference case with fine-scale bathymetry data of the Garonne River, France. The strength of the method lies in its applicability to noisy multi-satellite data while ensuring physical consistency. It should be applicable in real time to any river basin, using nadir altimetry only or combined to the forthcoming SWOT data. Moreover, the method allows to take full advantage, via the hydrodynamic model, of variable water masks observations and physical
\end{abstract}


segmentations of river networks. The method is implemented in the open source hydrodynamic data assimilation platform DassFlow.

\section{Introduction}

River discharge estimation is a key issue in hydrological sciences and water management, especially under the ongoing climate change. In order to characterize hydrological fluxes, river discharge is defined as an essential physical variable (see Global Climate Observing System (WMO, 2011, 1997)). Streamflow records are classically established at water level monitoring stations using Stage-Discharge (SD) laws derived from sparse in situ measurements of water levels and discharge. However, the number of gauging stations is decreasing worldwide (see Fekete and Vörösmarty [2007]). On the other hand, new generations of earth observation satellites provide an increasing hydraulic visibility of continental Water Surfaces (WS) variabilities (see Garambois et al. [2017], Montazem et al. [2019]). Dynamic estimates of WS Elevations (WSE) are derived from radar altimetry for large rivers (see recent reviews in Cretaux et al. [2017], Ricko et al. [2012]) or more recently from Lidar measurements (see O'Loughlin et al. [2016], Zwally et al. [2012]). Although only available at river cross-sections located at the intersection of a satellite nadir track with a river (so-called Virtual Stations, VS), multi-mission WS measurements are compiled to form relatively sparse but quickly improving global datasets (e.g. the Hydroweb project ${ }^{1}$ ). In addition to decades of nadir altimetry, the upcoming NASA/CNES SWOT mission (Surface Water Ocean Topography mission, expected to be launched in 2022) will provide an unprecedented near global dynamic mapping of river WS height, width and slope (e.g. Alsdorf et al. [2007], Biancamaria et al. [2016], Durand et al. [2010], Rodríguez et al. [2020], Rodriguez et al. [2018], Rodríguez et al. [2012]). Nevertheless, discharge estimation from satellite data remains a challenging problem because of: (i) nonlinear open channel flow physics and hydrological processes, (ii) their limited observability but also the sampling and quality of remote sensing data, (iii) uncertain or even unknown channel bathymetry and/or friction and/or lateral exchanges for many rivers, (iv) the correlated effect of those flow controls on the WS (observable).

Open-channel inverse problems have been studied relatively recently in a satellite data context and assuming more or less unknown hydraulic parameters (see Biancamaria et al. [2016] for a review and also Larnier et al. [2020] and references therein). Satellite altimetry measurement scales enable to observe mostly low Froude flows as remarked in Garambois and Monnier [2015]. The estimation of river discharge from satellite and ancillary data is investigated using flow models of different complexities, from simple algebraic models (e.g. Bjerklie et al. [2003, 2005], Durand et al. [2014], Garambois and Monnier [2015], Leon et al. [2006], Paris et al. [2016], Smith et al. [1996]) to dynamic and spatially distributed models with data assimilation systems (e.g. Biancamaria et al. [2011], Brisset et al. [2018], Paiva et al. [2013b], Pujol et al. [2020], Schneider et al. [2018], Wongchuig-Correa et al. [2020]), eventually combined to algebraic low complexity systems based on the low Froude model for real-time estimates [Larnier et al., 2020]. The present contribution originally combines the advantages of both approaches: (i) using a fine hydrologicalhydraulic river network model integrating, via variational data assimilation, multi-satellite data and (ii) enabling

to derive hydraulically meaningful local discharge laws adapted to backwater affected reaches and to operational discharge estimates from multi-mission altimetric data.

Concerning at-a-station discharge laws, Smith et al. [1996] calibrated width-discharge rating curves, i.e. hydraulic geometry relationships [Leopold and Maddock, 1953], from effective width derived from ERS1 SAR images of the braided Tanana River (Alaska) and discharges from a model. Next, a general flow resistance equation, similar to ${ }_{5}$ Manning equation and adapted to in bank river discharge estimation with remote sensing data, is proposed and adjusted using statistical methods and a ground based dataset in Bjerklie et al. [2003, 2005]. Recently, Birkinshaw et al. [2010] used the equations from Bjerklie et al. [2003], water depth estimated from altimetric data ERS-2 and

\footnotetext{
${ }^{1}$ http://hydroweb.theia-land.fr
} 
ENVISAT and WS width from Landsat imagery to estimate discharge on the Mekong River. In Paris et al. [2016], altimetric rating curves are calibrated using water levels at 711 ENVISAT and 209 Jason-2 virtual stations and o discharges simulated by the hydrological-hydrodynamic model MGB (portugese acronym of Modelo de Grandes Bacias, see e.g. Collischonn et al. [2007], Paiva et al. [2013a]) over the Amazon basin. Similar methodologies were subsequently applied on large basins such as the Congo River basin [Paris et al., 2020] and the Ogooue River basin [Bogning et al., 2020], but also on smaller scale basins [Andriambeloson et al., 2020]. Using a 1D hydraulic model of a $135 \mathrm{~km}$ reach of the Brahmaputra River validated on Saral/Altika altimetric data, Dhote et al. [2020] build simple rating curves at 4 virtual stations. For backwater affected river reaches, hence reaches with stage-discharge hysteresis, the method of Paris et al. [2016] uses WS slopes estimated from altimetric data to constrain the discharge estimation. Indeed, WS slope enables to measure the signatures triggered by transient flow effects and potential variable backwater from downstream conditions. WS slope is required in the so-called Stage-Fall-Discharges (SFD) law that is adapted to reaches with variable flow energy slope - see bibliography and SFD investigations using a Bayesian method with in situ data in Mansanarez et al. [2016] and with fine-scale hydraulic model outputs in Mansanarez et al. [2019].

However, an accurate WS slope estimation using altimetric data only remains difficult, because of measurements spatio-temporal sparsity and errors. Their physical extrapolation in space and time can be leveraged by using a fine river network flow model. Indeed, recent progress have been made in fine river network flow modeling using/assimilating multi-satellite data (e.g. Fleischmann et al. [2020], Garambois et al. [2020a], O'Loughlin et al. [2020], Paiva et al. [2013b], Pujol et al. [2020], Schneider et al. [2018]). These models enable a fairly good fit to the altimetric data (e.g. O'Loughlin et al. [2020], Pujol et al. [2020] respectively on the Congo and Amazon basins) and simulating realistic hydraulic signatures. Those have seldom been used to estimate stage-fall-discharge laws with simulated WS slopes, including at newly acquired virtual stations. Moreover, investigating simulated WS slope signatures at fine scale, in relation to river segmentation scales and hydraulic controls (cf. Montazem et al. [2019]), is relevant given the hydraulic visibility [Garambois et al., 2017] expected from the future SWOT mission at relatively long spatial wavelength for the slope terms especially for low slope rivers [Rodríguez et al., 2020]. A new method is presented here for deriving SFD laws from flow signatures simulated by a fine river network model in coherence with multi-satellite data, and using Bayesian optimization.

Reaching consistency between the hydraulic signatures simulated by a river network model and sparse multisatellite data is crucial to take advantage of their informative content. This can be achieved via data assimilation techniques. Recent studies investigate the assimilation of WS observables for hydraulic modeling and parameter inference, with sequential or variational methods (see review in Biancamaria et al. [2016]).

Concerning sequential methods, in Paiva et al. [2013b], the ensemble Kalman filter is applied to correct discharges simulated by the MGB large scale hydrological model over the Amazon basin via the assimilation of ENVISAT WS anomalies at 212 virtual stations. They also experiment the use of in situ discharge data from 109 gauges or altimetric discharge from 287 virtual stations from Getirana and Peters-Lidard [2013]. Emery et al. [2018] introduced a spatial localization treatment in the Kalman filter for correcting the storage and discharge of the ISBA-CTRIP model of the Amazon basin via the assimilation of discharges obtained with the altimetric rating curves of Paris et al. [2016] at 368 ENVISAT virtual stations. They point out the low temporal sampling of the ENVISAT data and the potential interest of combining multi-mission data, confirmed in Emery et al. [2020]. In Brêda et al. [2019], a hydraulically-based variance and covariance is introduced in the Ensemble Kalman filter method to assimilate multi-mission altimetry data in the MGB model and correct the effective river bathymetry.

The Variational Data Assimilation (VDA) approach (e.g. Cacuci et al. [2013] and references therein) used in the HiVDI inverse method Larnier et al. [2020] is well-suited to accurately infer hydraulic parameters of dynamic models (see Brisset et al. [2018], Larnier et al. [2020], Oubanas et al. [2018] with synthetic SWOT data and Garambois 
et al. [2020a], Pujol et al. [2020], Tuozzolo et al. [2019] also considering real data). It consists in fitting the hydraulic model response to observed WS variations by optimizing, in a variational framework, parameters among 55 in/outflows, channel bathymetry and friction. Recall that the simultaneous inference of all those flow controls in a shallow water model from WS observables only is an ill-posed inverse problem because of their correlated influence on WS (cf. Larnier et al. [2020]). Inferable channel parameters patterns but also inferable discharge frequencies given data spatio-temporal sparsity are investigated in Brisset et al. [2018] and Larnier et al. [2020] from synthetic SWOT data (dense in space) and in Garambois et al. [2020a] and Pujol et al. [2020] using ENVISAT or synthetic SWOT data. Hydraulic model construction from multi-satellite data and simultaneous inference of discharge and channel parameters using VDA is investigated on ungauged rivers in the Amazon basin in [Garambois et al., 2020a, Pujol et al., 2020]. A $71 \mathrm{~km}$ braided portion of the Xingu River with a single inflow [Garambois et al., 2020a] and a $800 \mathrm{~km}$ long reach of the Negro River with multiple inflows from MGB model Pujol et al. [2020] are studied with the DassFlow 1D hydraulic model [Brisset et al., 2018] and the HiVDI inverse method [Larnier et al., 2020].

Meaningful hydraulic signatures are obtained with a fairly good fit to altimetry data in Pujol et al. [2020] on a long and nearly ungauged river portion using a hydrological-hydraulic approach calibrated with VDA (DassFlow). This approach is therefore adequate to simulate fine hydraulic variability from sparse multi-satellite data and extrapolate SFD laws at any virtual station, including newly acquired ones.

Optimally combining sparse multi-mission altimetry data with a coupled hydrological-hydraulic model of river network via VDA is newly investigated here. Besides, it is newly addressed that the physically meaningful and "satellite compatible" flow signatures obtained, including WS slopes, enable to extrapolate altimetric SFD laws at any virtual station on the spatio-temporal domain.

In order to allow operational estimation of discharge from altimetry data, the present contribution proposes a rigorous methodology to estimate SFD laws amenable to sparse multi-mission altimetry data and reaches affected by variable friction slope. The proposed method is based on a river network hydraulic modeling performed with DassFlow-1D using inflows from the large scale hydrological model MGB, and calibrated on multi-mission altimetric data using VDA. A general SFD law is used and its parameters are estimated from altimetric data and hydraulic model outputs, including multi-scale WS slopes and discharge. These parameters are computed using a MCMC (Markov Chain Monte Carlo) algorithm that also enables to estimate the uncertainty (following Le Coz et al. [2014], Mansanarez et al. [2019], Paris et al. [2016]),

The method is applied on the Negro-Branco river network located in the Amazon basin and representing a challenging case including anabranching reaches, confluences and backwater affected reaches. The multi-satellite dataset contains altimetric data from Jason-3 and Sentinel-3A and -3B and covers the period from February 2016 to May 2019.

The added value of using model derived WS slopes to estimate rating curve parameters is investigated along with the link to "hydraulic geometry" coefficients and their spatial variations. The extrapolation of discharge outside the altimetry calibration set is tested.

The paper is structured as follows. Section 2 presents the different flow models and how they are calibrated. Section

3 introduces the study zone, the multi-satellite data and the different hydrological quantities computed by the river network flow model. Section 4 presents the numerical experiments and their results, and Section 5 is dedicated to discussions.

\section{Flow models and observables}

This section presents the flow models and the inverse method for integrating multi-satellite data and deriving

hydraulically meaningful flow lines, WS slopes and SFD relationships over a river network domain. The method is 
based on the following: (i) the 1D Saint-Venant river network flow model weakly coupled to the MGB hydrological model to account for spatially distributed hydrological fluxes, (ii) the computational inverse method HiVDI (see Brisset et al. [2018], Larnier et al. [2020]) enabling to calibrate the hydraulic model (of a large river network here) on multi-satellite data (see e.g. Pujol et al. [2020]), (iii) the SFD laws enabling to estimate discharge by taking into account (iv) the uncertainties from satellite data and the outputs of the hydrodynamic model. These components of our method are introduced in this section in the same order.

\subsection{River network flow model}

A river network domain $\Omega$ is described by connected close-line segments. For a flow cross-section orthogonal to the main (longitudinal) flow direction of curvilinear abscissa $x \in \Omega$ (distance from downstream), at time $t \in[0, T]$, let $A(x, t)$ be the flow cross-sectional area $\left[\mathrm{m}^{2}\right]$ and $Q(x, t)$ the discharge $\left[\mathrm{m}^{3} \cdot \mathrm{s}^{-1}\right]$ such that $Q=U A$ with $U(x, t)$ defined as the longitudinal cross-section averaged velocity $\left[m . s^{-1}\right]$. The 1D Saint-Venant equations in $(A, Q)$ variables at a flow cross-section write as follows:

$$
\begin{cases}\partial_{t} A+\partial_{x} Q & =k_{\text {lat }} q_{\text {lat }} \\ \partial_{t} Q+\partial_{x}\left(\frac{Q^{2}}{A}\right)+g A \partial_{x} Z & =-g A S_{f}+k_{\text {lat }} U q_{\text {lat }}\end{cases}
$$

where $Z(x, t)$ is the WSE $[m]$ and $Z=\left(z_{b}+h\right)$ with $z_{b}(x)$ the river bed level $[m]$ and $h(x, t)$ the water depth $[m]$, $g$ is the gravity magnitude $\left[m . s^{-2}\right], q_{l a t}(x, t)$ is the lineic lateral discharge $\left[m^{2} \cdot s^{-1}\right]$ and $k_{l a t}$ is a lateral discharge coefficient chosen equal to one here since we consider inflows only.

The friction term $S_{f}$ is classically parameterized with the empirical Manning-Strickler law established for uniform flows $\frac{|Q| Q}{K^{2} A^{2} R_{h}^{4 / 3}}$ where $K$ is the Strickler coefficient $\left[\mathrm{m}^{1 / 3} \cdot \mathrm{s}^{-1}\right], R_{h}(x, t)=A / P_{h}$ the hydraulic radius $[m], P_{h}(x, t)$ the wetted perimeter $[m]$.

Let us recall the Froude number definition $\mathrm{Fr}=U / c$ which compares the cross-section averaged flow velocity $U$ to 215 pressure wave celerity $c=\sqrt{\frac{g A}{W}}\left[m \cdot s^{-1}\right]$ where $W$ is the flow top width $[m]$.

The Saint-Venant equations (1) are solved on each segment of the river network and the continuity of the flow between segments is ensured by applying an equality constraint on water levels at the confluence between two segments.

Boundary conditions are classically imposed (subcritical flows here) at the boundary nodes with inflow discharges $Q(t)$ at upstream nodes and WSE $Z(t)$ at downstream node; lateral hydrographs $q_{l a t}(t)$ at in/outflow nodes. The initial condition is defined as the steady state backwater curve profile $Z_{0}(x)=Z\left(Q_{i n}\left(t_{0}\right), q_{l a t, 1 . . L}\left(t_{0}\right)\right)$ for hotstart. This 1D Saint-Venant model is discretized using the classical implicit Preissmann scheme (e.g. Cunge [1980]) on a regular grid of spacing $\Delta x$ using a double sweep method enabling to deal with flow regimes changes with a one-hour time step $\Delta t$. This is implemented in the DassFlow computational software [Monnier and Larnier, 2018].

\subsection{The computational inverse method}

The inverse method employed here to calibrate the spatially distributed friction against altimetric data is the VDA method presented in Larnier et al. [2020]. The principle of this inverse method is to estimate the (discrete) flow controls that minimize the discrepancy between the observed and simulated flow lines, $Z_{o b s}$ and $Z(k)$ respectively, the latter depending on the unknown parameters vector $k$ through the hydrodynamic model described in the section 2.1. In this study, the control vector consisting in spatially distributed friction patches is $k=\left(K_{1}, \ldots, K_{N}\right)^{T}$ as done in Garambois et al. [2020a], Pujol et al. [2020] and proposed in 2D in Monnier et al. [2016]. The water level 
discrepancy is measured with a classical quadratic cost function:

$$
j(k)=\sum_{p=1} \sum_{n=1}\left(Z\left(k ; x_{n}, t_{p}\right)-Z_{o b s}\left(x_{n}, t_{p}\right)\right)^{2}
$$
slope as:

$$
Q=\kappa S_{f}^{1 / 2}=\prod p_{i}^{\alpha_{i}}
$$

with $\kappa$ the conveyance (e.g. Dingman [2009]). The conveyance is inversely proportional to a friction parameter $\rho$ $\left(p_{1}=1 / \rho\right)$ and proportional to the product of flow parameters $p_{i}$ with the corresponding exponent $\alpha_{i}$ as written in

\footnotetext{
${ }^{2}$ see the documentation of the minimize function of the scipy.optimize library and its implementation of the LBFGS algorithm in https://docs.scipy.org/doc/scipy/reference/optimize.minimize-lbfgsb.html
} 
Rodríguez et al. [2020]. Note that an infinity of empirical parametrizations of flow resistance could be possible such as Chezy or Manning-Strickler ones for open channel flows (classical parameters values are recalled in the appendix, see Tab. 8).

Out of the inflow points and under the low Froude assumption in a satellite altimetry context ([Garambois and Monnier, 2015], typically Fr < 0.3), the momentum equation in the system (1) reduces to an equality between the WS slope $S=-\partial_{x} Z$ and $S_{f}$ which combined to Manning-Strickler parametrization (see Sec. 2) under steady state gives the low Froude equation:

$$
Q=K A R_{h}^{2 / 3} S^{1 / 2}
$$

Low Froude discharges will be denoted $Q_{l F r}$ in the following. For rivers with large width-to-depth ratio and assuming rectangular cross-sections, the above expression simplifies in $Q=K W h^{5 / 3} S^{1 / 2}=K W\left(Z-b_{l F r}\right)^{5 / 3} S^{1 / 2}$ with $W$ the river top width, $h$ and $Z$ respectively the flow depth and level, $b_{l F r}$ the effective river bottom elevation in the low Froude model. The low Froude model under the wide rectangular cross-sections assumption can be generalized into a SFD law:

$$
Q=\alpha W^{\beta}\left(Z-b_{s f d}\right)^{\gamma} S^{\delta}
$$

This SFD law enables to deal with stage-discharge hysteresis and is amenable to satellite observables. Note that with $\beta=1, \gamma=5 / 3$ and $\delta=0.5$, the general SFD defined by (5) corresponds to a low Froude model assuming wide rectangular cross-sections. Parameters of the general SFD model will be calibrated in the following using hydrodynamic model outputs integrating sparse satellite altimetry data and optical water masks. This river network model enables to simulate the required hydraulic quantities $Q$ and $S$, even outside the sparse spatio-temporal sample of altimetry data used for calibration. SFD discharges will be denoted $Q_{s f d}$ in the following - note that $\beta$ is set to 1 or 0 and some/all the other parameters will be optimized.

Note that SFD are estimated in Mansanarez et al. [2016] in a situ measurements context using piecewise SFD laws to handle the transition to backwater affected regime, and in Paris et al. [2016] in a satellite altimetry context without fine WS slope estimates. The present method uses a generalized SFD law and flow signatures from a hydrodynamic network model enabling to continuously handle flow conditions and non-linearities over a river network.

\subsubsection{Computation of SFD laws coefficients}

The coefficients of a SFD power law (5) can be computed at a point where the discharge and the flow vein features are known at times $t_{p}, p \in[1, \ldots, P]$ using optimization. One can choose to optimize more or less parameters depending on channel-flow complexity for instance (see Sec. 4.1.1).

Let $\eta$ be a subset of the set of parameters $\left\{\alpha, \gamma, \delta, b_{s f d}\right\}$. The goal is to find optimal SFD coefficients that satisfy $\eta^{*}=\arg \min _{\eta} \epsilon(\eta)$ with $\epsilon$ the quadratic error between the discharge computed using a SFD law (5) $Q_{s f d}$ and a target discharge $Q$ such that: $\epsilon(\eta)=\sum_{p=1}^{P}\left(Q\left(t_{p}\right)-Q_{s f d}\left(S, Z_{\text {obs }}, W ; t_{p} ; \eta\right)\right)^{2}$.

In the context of discharge estimation using WS elevations from altimetric data, the target discharge and the slope are the outputs of the river network model (see Sec. 3.3 and Sec. 3.1).

This optimization can be performed as long as the system to resolve is over-determined, i.e. when there are more observations than parameters $(\# \eta \leq P)$. Depending on the unknown SFD parameters in $\eta$ embedded in the SFD expression that is a product, the optimization problem is more or less difficult.

To compute SFD parameters and uncertainties, a widely used Bayesian inference method is chosen: the MonteCarlo Markov Chain (MCMC, see e.g. Gelman et al. [2013]) algorithm. Bayesian inference seeks to find the distribution of $p(\eta \mid Q)$ in our context. An MCMC algorithms enables to sample distributions using a Markov chain and its properties. The MCMC algorithm being based on the construction of a sampled distribution sequence, the 
algorithm has to be initialized and input and target distribution types chosen.$$
\begin{aligned}
& \text { the other parameters. As for the other parameters, the prior distributions of the standard deviation } \sigma_{1} \text { and } \sigma_{2} \text { are } \\
& \text { set uniform on a very large interval since no estimates are known. }
\end{aligned}
$$
set uniform on a very large interval since no estimates are known. deviation of the desired distribution provides an estimate of the uncertainty of the SFD relationship. If the uncertainty on the observations and on the SFD law parameters are known, the standard deviation of the desired distribution can be set by the user. However, when a part of the uncertainty is unknown, the expression of the standard deviation of the distribution can be specified and coefficients of the expression can be added as parameters to infer. Le Coz et al. [2014] discusses the use of affine standard deviations written $\sigma_{s f d}=\sigma_{1} Q+\sigma_{2}$ and such standard deviations are used in Mansanarez et al. [2016], assuming a constant standard deviation at low flows and linear at higher flows. We also use the same affine standard deviation and add $\sigma_{1}$ and $\sigma_{2}$ in the set of SFD parameters to be estimated using the MCMC algorithm.

Initial, prior distributions of the parameters are needed for the initialization. In Mansanarez et al. [2016], estimates of the parameters of the affine standard deviation are provided from (in situ) measurements and the estimation of the measurements error provides uncertainties. However, in the present ungauged context, we do not have such estimates for our coefficients and for the uncertainties. Hence, we use uniform distributions with parameters defining relatively wide intervals not to be restrictive (see Tab. 1). For the coefficients $\beta, \gamma, \delta$ and $b_{s f d}$, the uniform law is centered around the value given by the Manning-Strickler equation (4) and the boundaries are given by the experience (mostly, negative coefficients must be avoided). For the coefficient $\alpha$, the support is wider to compensate 年 set

\begin{tabular}{|c|c|c|c|c|c|c|}
\hline parameter & $\alpha$ & $\gamma$ & $\delta$ & $b_{s f d}$ & $\sigma_{1}$ & $\sigma_{2}$ \\
\hline distribution & $\mathcal{U}\left(0,10^{16}\right)$ & $\mathcal{U}\left(0, \frac{10}{3}\right)$ & $\mathcal{U}(0,1)$ & $\mathcal{U}\left(z_{b}-1.5, z_{b}+1.5\right)$ & $\mathcal{U}\left(0,10^{6}\right)$ & $\mathcal{U}\left(0,10^{6}\right)$ \\
\hline
\end{tabular}

Table 1 - Parameters of the SFD law (5) and associated prior distributions.

The MCMC provides a sampled distribution of the different parameters. The parameters are then estimated from this discretized distribution by the Maximum A Posteriori (MAP, see e.g. Gelman et al. [2013]) estimation of the expected value.

330 The choice of the subset $\eta$ (i.e. the sought parameters of the SFD law (5)) and the estimation of the slope are explored in the following.

\section{Study zone and calibrated river network model}

The study zone consists of a real branched river network in the Amazon basin for which are available a large scale hydrological model and a rich multi-satellite dataset composed of multi-mission altimetric data and optical observations. An effective river network hydraulic model is set up in coherence with both hydrological fluxes and satellite observations of river surface deformations. This model will then be used as spatio-temporal extrapolator of hydraulic variables, especially slope and discharge. This extrapolation will enable to compute SFD law's coefficients (as in Sec. 2.3.2) and hence to estimate the discharge on the river network domain.

\subsection{Study area and multi-satellite data}

The Negro-Branco River network This river network has to be chosen because of its size, complexity and satellite observability. 
We focus on one of the major rivers in the Amazon basin and in the world, the Negro River. We consider the reach that is upstream of the city of Manaus (where the Negro River encounters the Solimoes River to form the Amazon River) up to Sao Gabriel da Cachoeira $(860 \mathrm{~km}$ long reach). We also consider its major tributary the Rio Branco 1).

Note that the confluence with the Solimoes river triggers strong backwater controls, mostly affecting the downstream part of this river network (see analysis in Montazem et al. [2019], Pujol et al. [2020]).

At their upstream point, the drained area of the Rio Negro and Rio Branco are respectively around $209000 \mathrm{~km}^{2}$ and

$9700 \mathrm{~km}^{2}$. At the Negro-Branco confluence, the area drained by the network is about $596000 \mathrm{~km}^{2}$ while it reaches $704000 \mathrm{~km}^{2}$ downstream at Manaus.

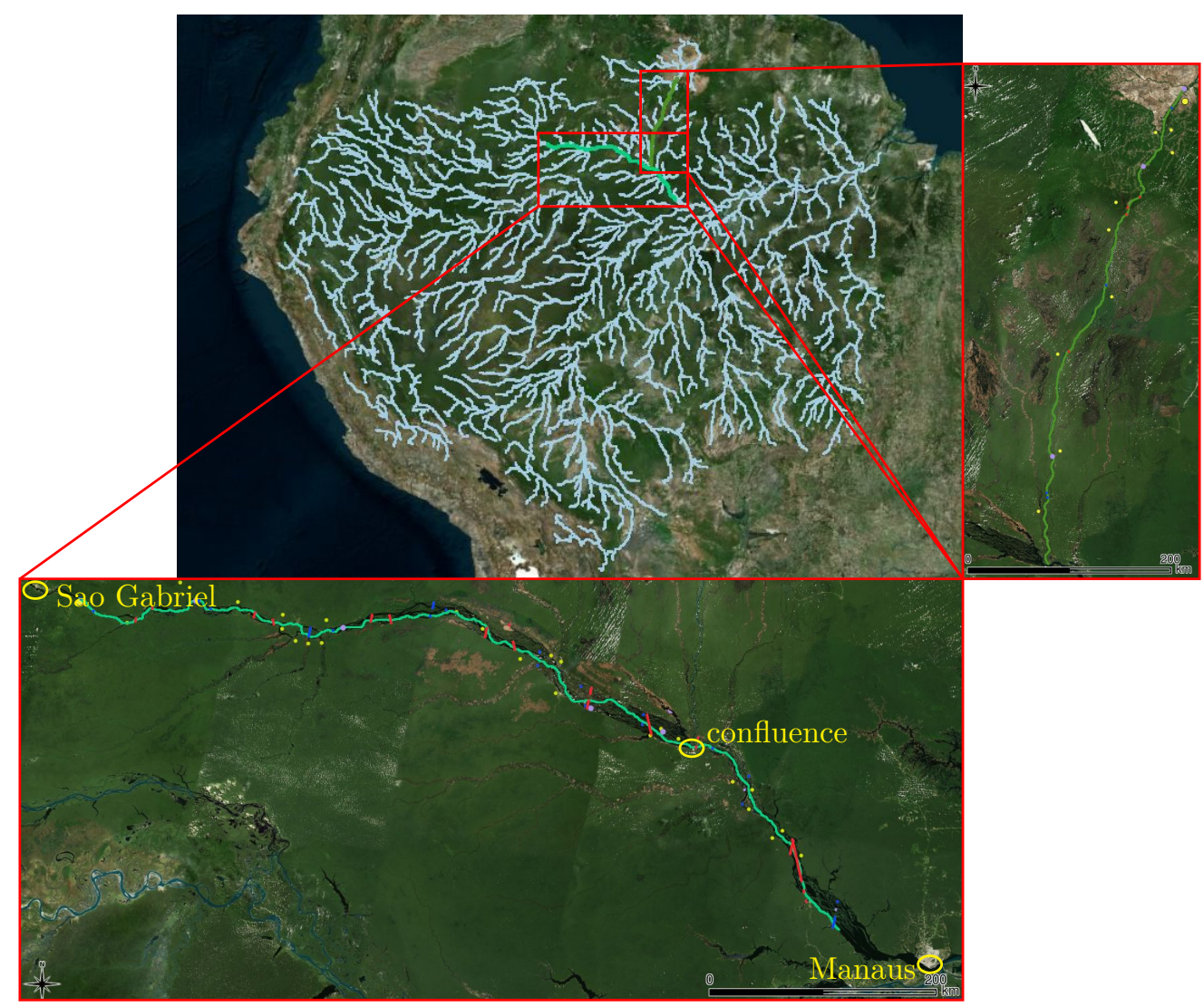

Figure 1 - Study zone and observability: the Negro-Branco River network in the Amazon basin with hydrological inflow points in yellow, and multi-mission virtual stations locations - S3A stations in blue, S3B stations in red and J3 stations in purple.

Altimetric data The used multi-satellite database of WSE is composed of altimetric observations of Jason-3 (J3), Sentinel-3A and -3B (S3A and S3B) satellites.

The satellite $\mathrm{J} 3$ orbit provides data every 10 days while the satellites S3A and S3B provide data every 27 days. Two consecutive tracks are separated at the equator by $160 \mathrm{~km}$ for $\mathrm{J} 3$ and $100 \mathrm{~km}$ for S3A and S3B. The intersections between the satellite tracks and the river define the virtual stations (VS), respectively 7, 22 and 22 with J3, S3A 
and S3B ground tracks (see VS on 1).

These data cover a time window between March 2016 and September 2020 and the space time representation (see

Fig. 2) highlights the observed flow signatures variabilities: typical inter-annual variations with seasonal floods in this tropical hydrological regime (the highest flow is around $t=1200$ days and the lowest around $t=600$ days).

This map also illustrates the sparsity of the data that is reduced considering multi-missions satellite data. However, the spatio-temporal resolution is still insufficient to compute accurate reach scale WS slopes (especially on the Rio Branco which presents a North-South pattern with comparatively less intersections with satellite ground tracks).

A drawback of using multi-mission datasets lies in the difficulty to estimate accurate inter-mission biases. A rough estimate of this bias is obtained by comparing the time series at cross-overs and is applied to the altimetric data to ensure the compatibility from one VS to another.

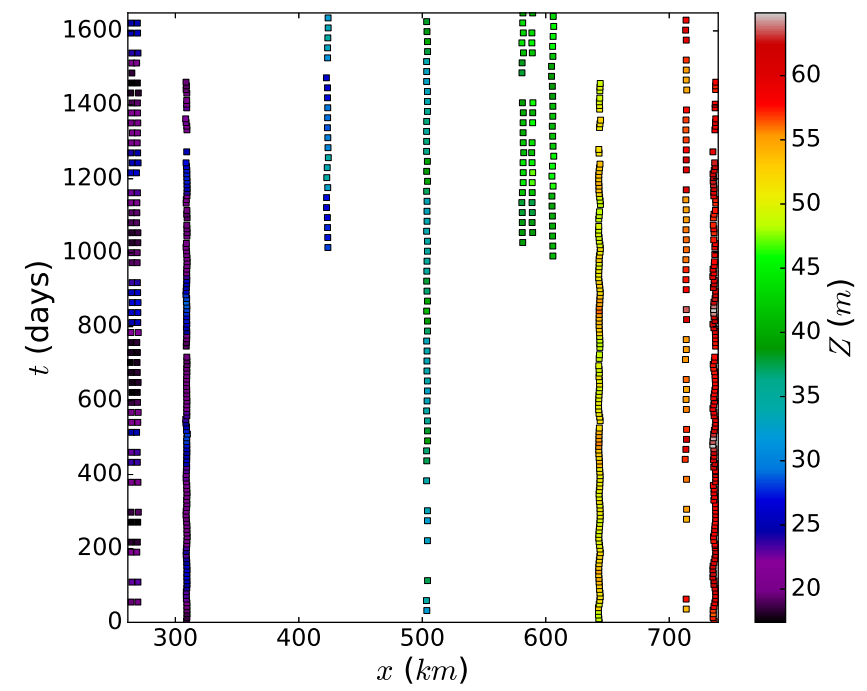

(a) Rio Branco

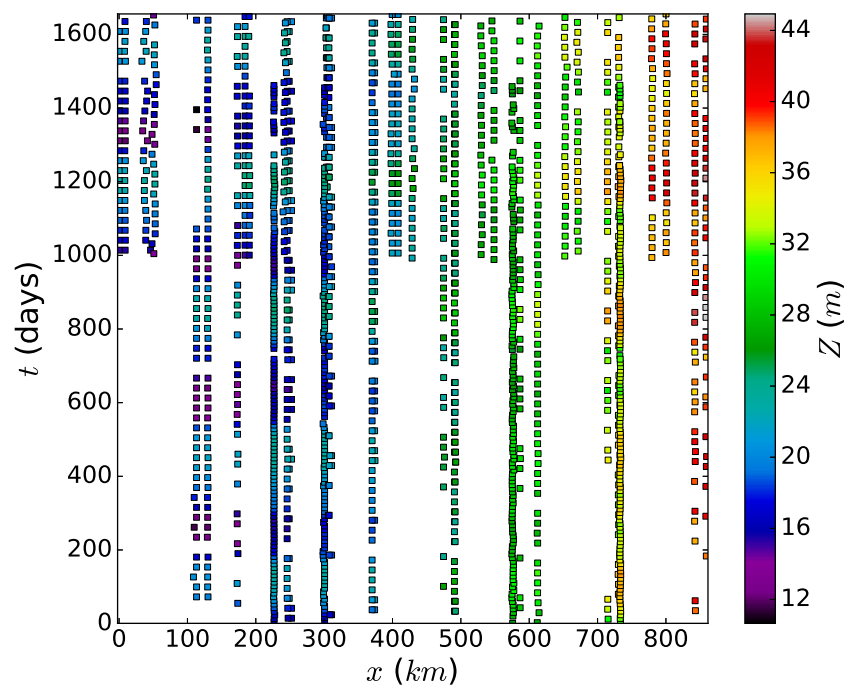

(b) Rio Negro

Figure 2 - Time and space map of the free surface elevation from multi-mission altimetric observability. The J3 stations are recognizable by the temporal density of the data at a station $(x \approx 300 \mathrm{~km}$ on the Rio Branco for example) and the S3B stations by the beginning of the mission around $t=1000$ days $(x \approx 600 \mathrm{~km}$ on the Rio Branco for example).

River width In order to build an effective hydraulic model, longitudinal river width variations are estimated (as in Pujol et al. [2020]) at each VS using the Peckel water mask (see Pekel et al. [2016] and Fig. 1). For anabranching river sections, the effective width consists in the sum of the top width of all channels at the virtual station.

\subsection{Construction of the hydrodynamic model}

In order to estimate the spatio-temporal variations in discharge and WSE from the Saint-Venant flow equations (1), one needs to provide boundary conditions and channels parameters. That is here (fluvial flows) an estimation

of the upstream inflow discharge hydrograph, the lateral inflow discharge hydrographs and the downstream water level, as well as river channel bathymetry and friction. Recall from Sec. 2.1 that the initial condition is set as 
the steady state backwater curve profile, the uneven spatial step $\Delta x \approx 200 \mathrm{~m}$ and the time step $\Delta t=1 \mathrm{~h}$. Given the multi-satellite dataset of WSE and width longitudinal profile, an effective 1D hydraulic model is set up on the Negro-Branco River network, including anabranching portions, following the methodology proposed in Pujol et al. [2020].

Hence, the model consists in (i) a 1D Saint-Venant model (1) applied here on a large branched network (ii) based on effective cross-sections defined from multi-satellite data and (iii) inflowed by the large scale hydrological model MGB (see Collischonn et al. [2007], Paiva et al. [2013b], Pontes et al. [2017]).

Hydrology-hydraulics setup (MGB-DassFlow network): The hydraulic model is inflowed with MGB time series at daily time step upstream of the river domain (2 inflows) and at 24 tributaries for the Negro River and 9 tributaries for the Branco River. These inflows correspond to the 35 catchment cells inflowing the Negro-Branco river network cells in the large scale hydrological model MGB (see Collischonn et al. [2007], Pontes et al. [2017]). In our hydraulic model DassFlow, only inflows are considered in this study. Some relatively small negative discharge (698 negative values over 45804 values and on 13 of the tributaries) values are thresholded to 0 . This is a reasonable hypothesis given small outflows (locally the highest outflow is less than $4.9 \%$ of the minimal discharge in the main channel) and because the scope is not to study the hydrological functioning of the basin but effective SFD laws inference in relation with hydraulics controls. These daily time series cover the time window between mid March 2016 and end of September 2020.

Effective 1D river channels construction An effective 1D river channel is built from the available multisatellite data (altimetry and width) at virtual stations following Garambois et al. [2017] and Pujol et al. [2020]. The cross-section shape is rectangular which is a reasonable hypothesis given the high width-to-depth ratio of the Negro River (see Latrubesse and Franzinelli [2005]). The effective cross-sections width $W$ is imposed at virtual stations from the top width measured from the (optical) water mask presented above.

The unknown channel bottom elevation $z_{b}$ in (1) or equivalently $b_{s f d}$ in (5) is obtained following Pujol et al. [2020] using the effective bottom elevations from altimetric discharge laws (see Paris et al. [2016]) with $\beta=0$ and $\delta=\frac{1}{2}$ in the SFD law (5). The calibration of the hydraulic model is done using the WSE $Z_{\text {obs }}$ (at every VS and on a time window between March 2016 and $1^{\text {st }}$ January 2019, see Fig. 2) and the discharge computed by MGB (see previous paragraph). Hence, a reference bathymetry $z_{b}$ is obtained at the altimetric virtual station/satellite scale.

Due to the lack of information out of the VS at the scale of current altimetric data, the channel shape is linearly interpolated in-between the VS in order to provide an effective channel geometry in the network. It contains the required complexity, including stage-discharge hysteresis, given the scope of this paper. This complexity is enough for a meaningful hydraulic calibration and for deriving SFD laws, at any VS located in the river network domain $\Omega$ and time window, using hydraulic signatures (see slopes in Fig. 3).

Effective friction calibration from multi-mission altimetry A calibration of the river network model is performed in order to fit it as well as possible to the altimetric observations. The river network model (1) is inflowed with MGB discharge time series. Its downstream boundary condition is set using the water level time series from the most downstream altimetric VS. The model is fitted on altimetric data at virtual stations using the inverse method explained in section 2.2. The control vector consists in spatially distributed friction coefficients as done in Garambois et al. [2020a], Pujol et al. [2020]. Constant friction patches are defined for each reach in-between two consecutive virtual stations (dashed lines on Fig. 3) to avoid over-parameterization while having enough free parameters to fit spatially distributed altimetric time series. Hence, the control $k=\left(K_{1}, \ldots, K_{N}\right)$ is composed of constant Strickler friction coefficients on the $N$ patches of the river domain defined in-between the $N$ altimetric virtual stations that will be considered for the calibration of the hydrodynamic model. 
The time period considered for calibration consists in the 117 first days corresponding to a wide range of flow regimes. This time window implies that the calibration is performed on the S3A and J3 data (resp. blue and green dashed lines on Fig. 3, 29 virtual stations and not using the S3B data, cyan dashed lines on Fig. 3). The optimal Strickler coefficients (red lines on Fig. 3) are consistent with usual values (between 5 and 40) and especially those found in Pujol et al. [2020] on the Negro River with ENVISAT data. Note that in the present case, a calibration over the whole first year, that is including annual flood propagation and recession dynamics, leads to a similar friction pattern. Hence the simulated hydraulic variabilities include similar hysteresis and the slope profiles are very similar. Finer altimetric datasets with unstationary estimates of data uncertainties would be needed to perform more advanced calibrations.

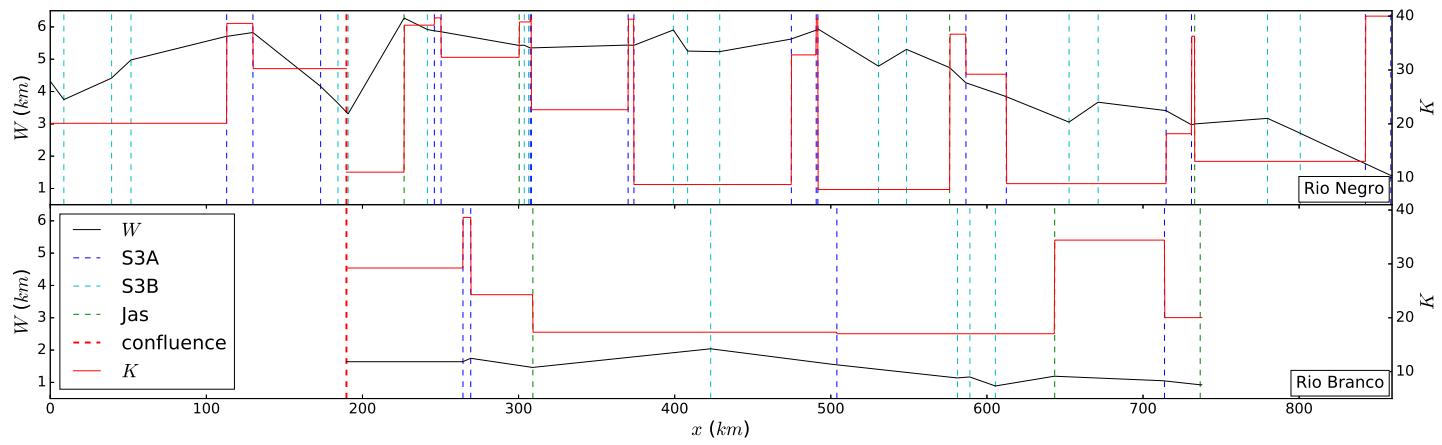

Figure 3 - Spatial patterns of channel parameters of the river network hydraulic model: width $W$ determined from water extent images, Strickler friction coefficient $K$ calibrated against altimetric data (control points at the virtual stations). The dashed vertical lines are the location of the VS (blue and cyan for resp. Sentinel-3A and -3B, and green for Jason-3) and the location of the confluence of the Negro-Branco river network (in red).

\subsection{Space-time simulation of hydraulic quantities with the river network model}

The set of coefficients $\eta$ of a SFD law (5) is calibrated using the MCMC calibration method presented in Sec. 2.3.2, considering the WSE time series of $Z_{o b s}$ at a given satellite virtual station, the target discharge $Q_{s w}$, and the WS slope $S$ of the river network model at satellite observation times.

As a matter of facts, accurate discharges and slopes are hardly inferable at fine scale from satellite altimetry data only. Indeed, the spatio-temporal sparsity of altimetric data prevents to estimate accurate slopes which may be insufficient to capture the influence of hydraulic controls (see Sec. 3.1 and Fig. 2).

Moreover, we seek a method that is easily adaptable if new satellite or in situ measurements are available.

Those missing hydraulic quantities can be extrapolated from the calibrated hydraulic model (see Sec. 2.1) at any time given hydrological forcings and at each numerical node over the whole river network domain. It enables to simulate, physically meaningful WSE, slopes and discharges in coherence with both altimetric observations and hydrological inflows.

The hydraulic quantities simulated by this river network model are analyzed here. Such a hydrological-hydraulic model of a river network, integrating multi-satellite altimetry data via assimilation, can be viewed as a powerful spatio-temporal extrapolator. 


\subsubsection{Hydraulic quantities from the calibrated river network model}

${ }_{445}$ The WSE $Z_{s w}$ simulated with the calibrated river network model are relatively close to the altimetric observations $Z_{\text {obs }}$ (see Fig. 4): the average difference is about $53 \mathrm{~cm}$ and on the bottom of Fig. 4 , more than $80 \%$ of the points are within the interval $Z_{o b s} \pm 1 \mathrm{~m}$. Moreover, just a few points are out of the interval $Z_{o b s} \pm 2 \mathrm{~m}$. Fig. 4 highlights that the $Z_{s w}$ out of the interval $Z_{o b s} \pm 1 \mathrm{~m}$ are mostly on the Rio Branco and especially at one particular virtual station (denoted by a blue rhombus on Fig. 4).

These errors are consistent with those found in other studies (e.g. O'Loughlin et al. [2020], Pujol et al. [2020]) and recall that between 0.2 and $1.5 \mathrm{~m}$ height error are often reported for altimetric data over rivers (e.g. Kittel et al. [2021], Ricko et al. [2012], Schwatke et al. [2015], Silva et al. [2010]). Moreover, these errors have been reduced for last generation satellites.

The flow modeling errors stem from the following uncertainty sources: (i) the modeling hypothesis with respect to real flow physics, (ii) inflow discharges from the regionalized MGB hydrological model, (iii) simplified channel geometry, (iv) satellite data errors.

Note that on the figures 5, the river network model seems to underestimate the WSE in comparison with the observations, which may come from the calibration time window. For example, the misfits of more than $2 m$ between some simulated and observed WSE are all located at one station denoted by blue rhombus on the figures 4 (located on the Rio Branco at $x=643 \mathrm{~km}$ ) and may stem from combined uncertainties (as previously mentioned). Finally, the calibrated hydraulic network model can be seen as a way to get physically meaningful flow lines that go through a noisy altimetric data cloud.

The simulated outputs of the river network model contain real-like flow complexities such as stage-discharges hysteresis, as shown on the left of Fig. 5 for some virtual stations. It illustrates the hysteresis from the $Z_{s w}, Q_{s w}$ hydraulic model outputs, which stems from variable backwater effect or transient flow. Recall that our hydraulic network model is inflowed with 37 discharge hydrographs representing different temporal signals of mass input that can be responsible for complex upstream-downstream propagation of information and corresponding WS signatures (cf. analysis in Pujol et al. [2020] on the Negro River). For example, the inflow signal from a tributary can be out of phase with the one of its confluent and responsible for variable backwater as it is the case downstream of the Negro River as highlighted on Fig. 5a downstream of the Negro River at $x=250 \mathrm{~km}$. Figure 6 summarizes the spatio-temporal variability of the flow lines simulated on the two river network branches along with inflow points and confluence location. 


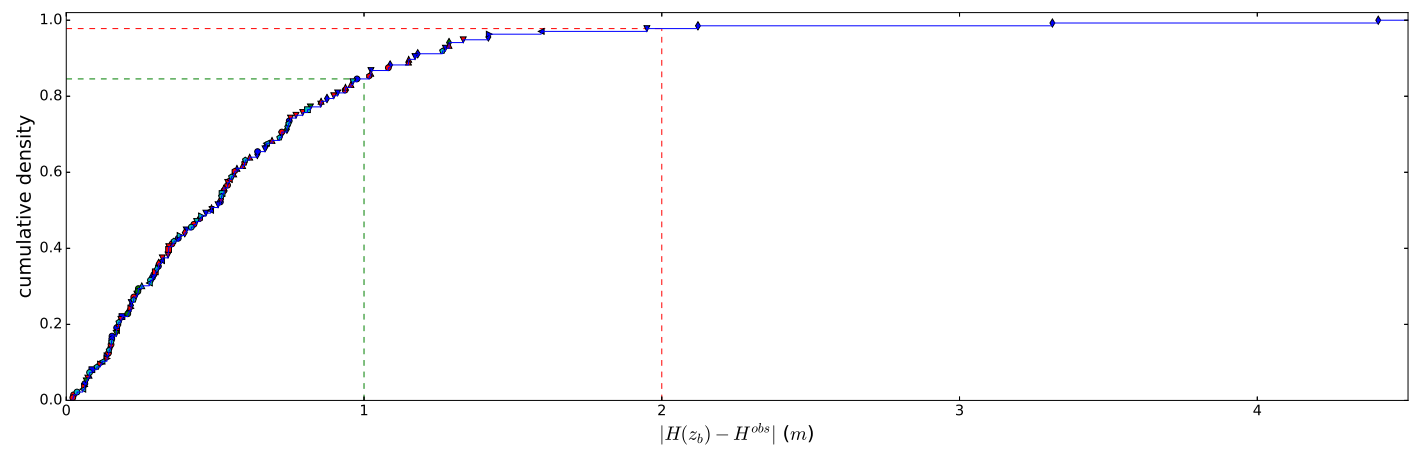

(a) Cumulative density of the absolute error.

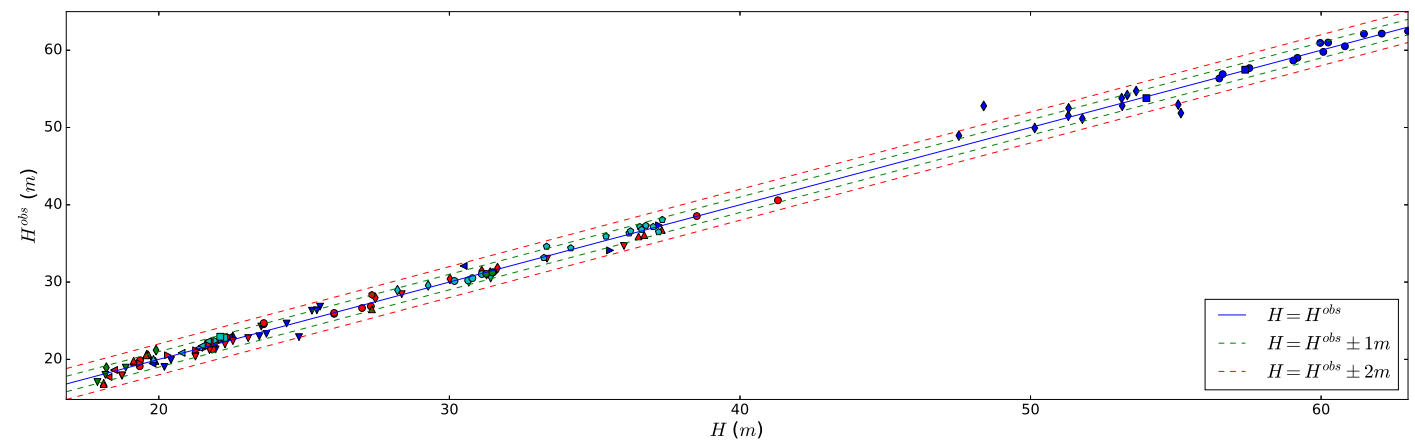

(b) Calibrated model output vs observation.

Figure 4 - Comparison of simulated and observed water surface elevations at virtual stations on the whole dataset using the calibrated river network model. For each VS station a different symbol is used, in blue for the Rio Branco, in green for the downstream segment of the Rio Negro and other colors for the upstream segment of the Rio Negro. 

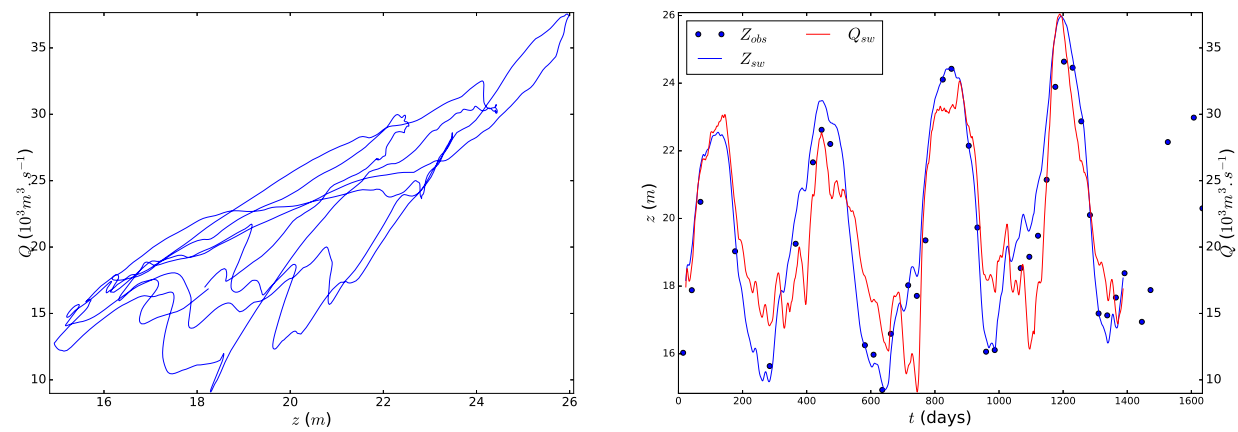

(a) $x=250 \mathrm{~km}$, Rio Negro (S3A VS).
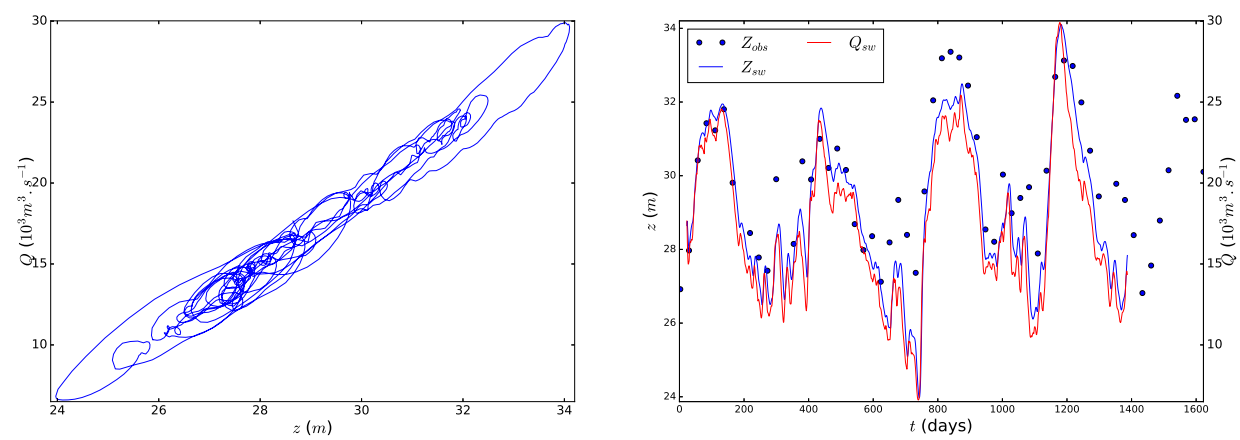

(b) $x=612 \mathrm{~km}$, Rio Negro (S3A VS).
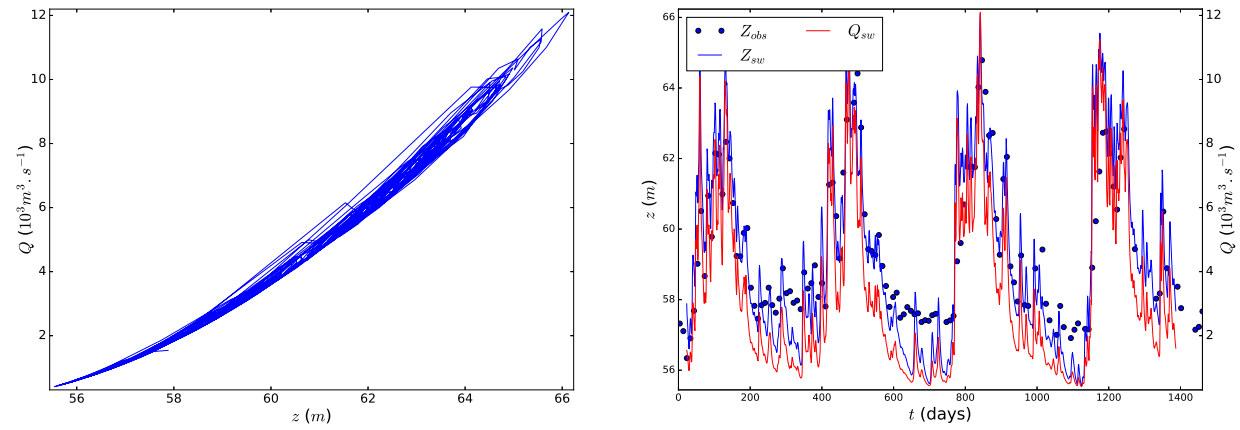

(c) $x=736 \mathrm{~km}$, Rio Branco (J3 VS).
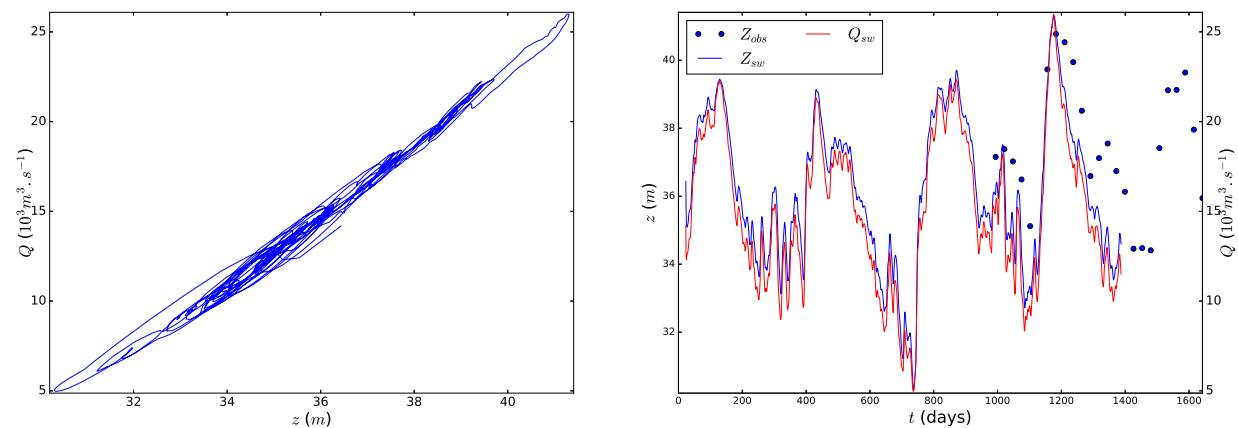

(d) $x=779 \mathrm{~km}$, Rio Negro (S3B VS).

Figure 5 - Simulated stage-discharge hysteresis at the hourly time step over the whole time period of 4 hydrological years investigated $\left(Z_{s w}\right.$ versus $Q_{s w}$ ) (left column) and temporal variations of simulated versus observed water levels $\left(Z_{s w}, Z_{o b s}\right)$ and simulated discharge $Q_{s w}$ (right column) at virtual stations of interest. 


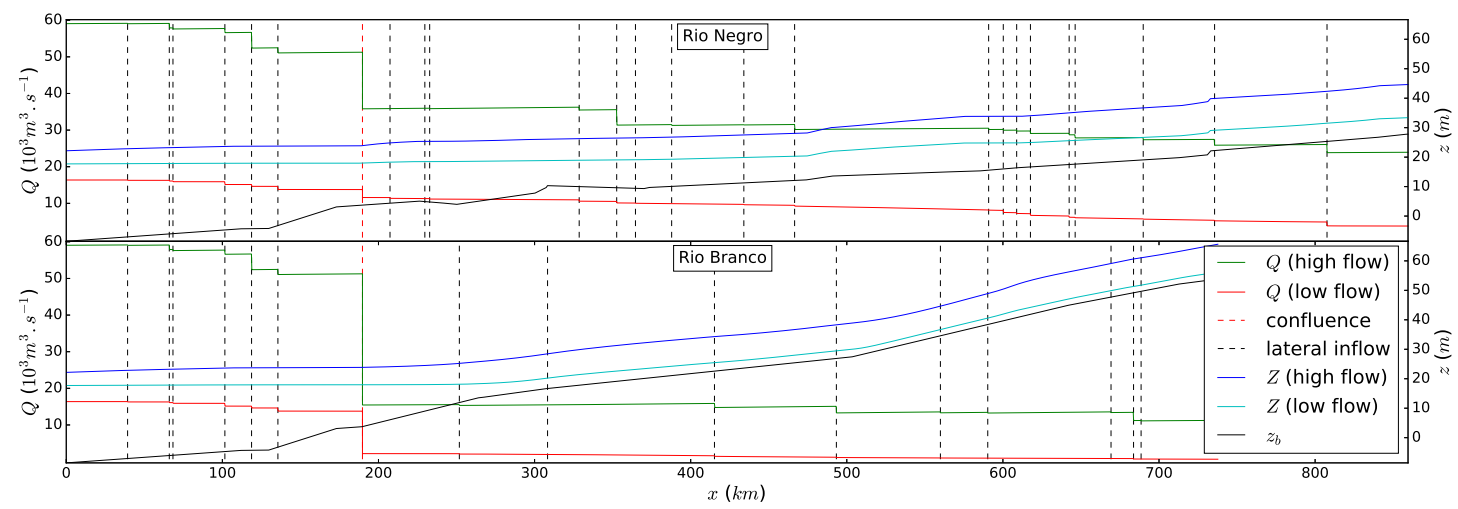

Figure 6 - Discharge and WSE simulated with the calibrated 1D Saint-Venant river network model for high and low flow on the Rio Negro (upper figure) and on the Rio Branco (with the downstream part of the Rio Negro, lower figure). The black dashed lines correspond to the locations of the lateral inflows and the red one to the location of the confluence of the Negro-Branco river network.

\subsubsection{Slope computations}

One crucial flow variable needed for estimating discharge from SFD laws is the downstream WS slope $S$. The river network model calibrated on sparse multi-satellite data provides flow lines including nonlinear spatio-temporal variations and stage-discharge hysteresis induced by the considered hydraulic controls. In order to investigate the impact of the slope estimation on the SFD laws, the following WS slopes are then derived at different scales using the flow lines of this river network model.

- Hydraulic (fine) scale: a slope calculated at fine spatial scale from the numerical grid of our numerical river network model, between two successive nodes whose spatial spacing is $\approx 300 \mathrm{~m}$. Because of the fluvial nature of the considered flows and downstream hydraulic control, the slope is estimated from simulated WSE $Z$ with a standard downstream finite difference at a given time. This fine scale estimate of the slope will be denoted $S_{f s}$. It is the finest slope that can be estimated here using the free surface elevation simulated with the 1D Saint-Venant network model at the numerical grid scale.

- Reach (large) scale: a reach averaged WS slope such as those expected from the future SWOT mission averaging at several kilometers in length of a river to reduce measurement noise (see Rodríguez et al. [2020]). The estimation of the slope at this scale is computed by averaging the fine scale slope, computed previously, over a $10 \mathrm{~km}$ reach downstream within the altimetric grid. This estimate of the slope will be denoted $S_{l s}$. In the context of rivers' altimetry, a large scale slope $S_{l s, \sigma}$ including synthetic measurement errors is also considered.

The resulting WS slopes are summarized on Fig. 7 and show real like spatial and temporal variations. The difference between the large scale and the fine scale slope stems from the WS curvatures, due to hydraulic controls [Montazem et al., 2019], on the averaging length.

Note that the slope at the finest scale (on the top of Fig. 7), is discontinuous because the Strickler friction coefficient is set to be piecewise constant (see figures 3) and each lateral inflow also introduces a small discontinuity. Under the low Froude assumption, the momentum equation of the Saint-Venant system (1) is $S_{f}=S+\frac{1}{g A} k_{l a t} U q_{l a t}$, which 


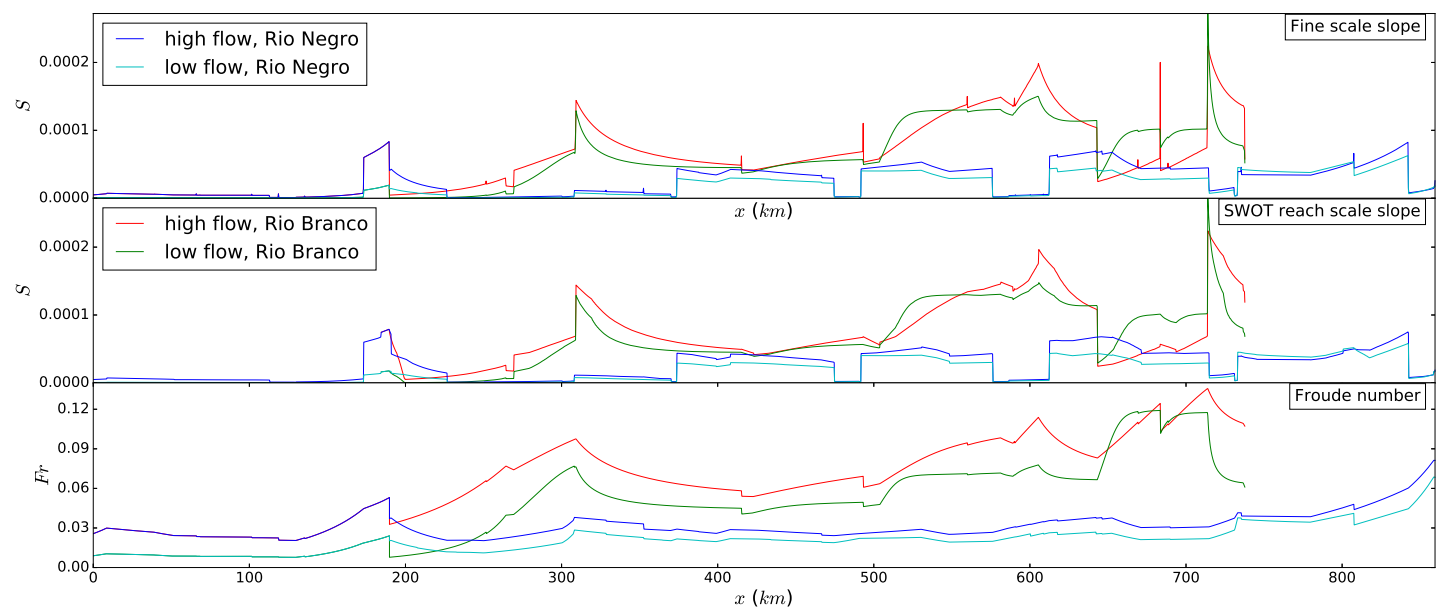

Figure 7 - Slope signatures simulated by the calibrated 1D Saint-Venant river network model over the Rio Negro and Rio Branco for high and low flow: WS slopes at fine scale (downstream finite difference on the numerical grid) and spatially averaged at "SWOT reach scale" (10km averaged slope in the altimetric grid). Corresponding Froude numbers are given in the lower pannel.

indeed implies the slope is discontinuous at the locations of the inflows. However, we suppose that the inflows are located between the reaches and we focus on the inside of those reaches. As said previously, the $S_{l s}$ reach scale slope is computed here at a $10 \mathrm{~km}$ downstream averaging length of the fine scale slope, inside the altimetric grid not to create artificial slopes variations between slope discontinuities (see the calibration grid of the Strickler coefficient in Fig. 3). The noised large scale slope $S_{l s, \sigma}$ is computed as $S_{l s}$ but using WSE plus Gaussian noise $\mathcal{N}\left(0, \sigma^{2}\right)$ with $\sigma=10 \mathrm{~cm}$.

Locally (at a VS), the difference between the large scale and the fine scale slope (both on the top figures of Figs. 8a, $8 \mathrm{~b}, 8 \mathrm{c}$ and 9$)$ keeps, on the whole time window, the same sign. It can be explained by the fact that the curvature keeps locally (downstream of the VS) the same sign on the whole time window. Hence, one can deduce a trend between the fine and large scale slope. The link between the WS curvature and hydraulic control is studied in details in Montazem et al. [2019].

\subsubsection{Extrapolation of the discharge}

The altimetric WSE $Z_{o b s}$ and the reference discharge $Q_{s w}$ from the river network model are used to calibrate SFD laws. Consequently, the calibrated SFD will take into account the noisy altimetric data and produce model-like discharge estimates. In Mansanarez et al. [2016], the discharge target used for SFD calibration stems from in situ measurements whose error is estimated to be a Gaussian noised with a given standard deviation $\sigma_{m}$. Assuming the measurements errors and the rating curve errors are independent, the standard deviation of the distribution of $Q$ is chosen here as: $\mu_{Q}=\sqrt{\sigma_{m}^{2}+\sigma_{s f d}^{2}}$. In the context of extrapolating hydraulic variables from the network model, the standard deviation of the reference discharge is obtained from the output of the network model and hence depends on all uncertainties introduced by and in the model.

The numerical experiment design is detailed hereafter, including the choice of SFD parameter sets to optimize. 


\section{SFD calibration and analysis}

We now present the investigations on the calibration of SFD laws and their use for discharge estimation. The spatiotemporal extrapolation of hydraulic quantities is performed using the river network model optimally combined with the satellite altimetric observations of the complex Negro-Branco River network.

\subsection{Numerical experiment design}

An experimental design is proposed to investigate the calibration of SFD laws from altimetric data $Z_{\text {obs }}$ and target discharges $Q_{s w}$ and WS slopes $S$ simulated with the Negro-Branco River network model used as a spatio-temporal extrapolator (see Sec. 3.3). Tests are performed at some VS representing different flow complexities, using more or less SFD parameters in calibration as explained here.

\subsubsection{SFD and SD variants considered}

In order to investigate the ability of SFD laws to capture flow variabilities, the calibration of the general SFD model (5) and the resulting performance in the estimation of the discharge are studied considering various parameters sets $\eta$. Several configurations are tested with more less SFD parameters optimized at the same time, from a classical SD relationship (see Mansanarez et al. [2016], Paris et al. [2016]) with $\eta=\left(\alpha, \gamma, b_{s f d}\right)$ and $\delta=0$ to the complete set of SFD parameters $\eta=\left(\alpha, \gamma, \delta, b_{s f d}\right)$ including a free exponent for the slope (see $\eta$ sets considered in Tab. 2). A SFD configuration with $\delta=0.5$, as the slope exponent in the low Froude model (4), is also tested. For all tested configurations, the exponent of the width is set to $\beta=1$ so that the effective width (rectangular cross-sections from satellite water masks here) is taken into account and the coefficients $\alpha$ can be compared to an effective Strickler coefficient (hence denoted $\alpha$ in Tab. 3 for the sake of comparison).

A reference low Froude law is also calibrated using the fine scale WSE $Z_{s w}$ and the slope $S_{f s}$ simulated with the river network model. The resulting estimation of the discharge is the best estimation that a low Froude or SFD law can provide locally. Since only noise-free data are used, the gap between the discharge estimated by the reference low Froude and by the river network model is only the results of the Low Froude hypothesis.

Parameter sets $\eta$ of the SFD model (5) are estimated using the MCMC algorithm, which also provides uncertainties on the estimated quantities. Since we also aim to investigate SFD parameters compensations arising when they are optimized simultaneously, a deterministic nonlinear least square algorithm is also used ${ }^{3}$.

The numerical experiments are summed up in Tab. 2 which details the parameters sets optimized along with the input data considered for the various SFD laws, the reference and estimated discharge from the low Froude equation.

\footnotetext{
${ }^{3}$ the deterministic nonlinear square algorithm of the scipy.optimize library least_squares, see documentation https://docs.scipy. org/doc/scipy/reference/generated/scipy.optimize. least_squares.html
} 


\begin{tabular}{|l|l|l|l|}
\hline notation & law & parameters & inputs \\
\hline$Q_{\text {ref }}$ & $(4)$ & $K$ & $Z_{s w}, S_{f s}$ \\
\hline$Q_{s f d}$ & $(5)$ & $\left(\alpha, \gamma, \delta, b_{s f d}\right)$ & $Z^{o b s}, S_{f s}$ \\
& & $\left(\alpha, \gamma, \delta, b_{s f d}\right)$ & $Z^{o b s}, S_{l s}$ \\
& & $\left(\alpha, \gamma, \delta, b_{s f d}\right)$ & $Z^{o b s}, S_{l s, \sigma}$ \\
& & $\left(\alpha, \gamma, b_{s f d}\right)$ & $Z^{o b s}$ \\
& & $\left(\alpha, \gamma, b_{s f d}\right)$ & $Z^{o b s}, S_{f s}, \delta=0.5$ \\
\hline$Q_{l F r}$ & $(4)$ & $K$ & $Z^{o b s}, S_{f s}$ \\
& & $K$ & $Z^{o b s}, S_{l s}$ \\
& & $K$ & $Z^{o b s}, S_{l s, \sigma}$ \\
& & $K$ & $Z^{o b s}$ \\
\hline
\end{tabular}

Table 2 - Summary and notations of the different discharge estimations performed with various SFD parameter

sets and inputs (hydraulic signatures including multiscale WS slopes).

\subsubsection{Selection of altimetric virtual stations for SFD estimation}

The estimation of the discharge depends on the hydraulic context of a virtual station resulting in more or less nonlinearities in the WS variabilities, including variable friction slope and stage-discharge hysteresis reflected in WS slope signatures. Hence, the following three VS are chosen to illustrate diverse hydraulic contexts among the S3A and J3 stations in function of flow signatures (see Fig. 7) and the hysteresis behavior.

- A first station is chosen on the downstream part of the Rio Negro (or just above the confluence with the Rio Branco), where the slope and the Froude number are rather low. On this section, the hysteresis behavior is not negligible (due to the strong backwater of the Solimoes river on the Rio Negro, see Sec. 3.1).

- A second station is chosen on the upstream part of the Rio Branco, where the slope and the Froude number are the highest. At this location, the hysteresis behavior is quite low and the left figure of Fig. 5c seems to be close to a power law between $Z$ and $Q$.

- A third station is chosen on the far upstream part of the Rio Negro, where the Froude number is still quite low but the slope is a bit higher. The relation between $Z$ and $Q$ (see left figure of Fig. 5b) is relatively linear but there are important lateral inflows nearby (around $3 \sim 5 \%$ of the total discharge at the inflow location) with different temporal signals (implying the more complex structure of the stage-discharge hysteresis curve, see Sec. 3.3.1).

A S3B station is chosen to test the spatial extrapolation of SFD. A good candidate is a virtual station rather far from any S3A or J3 station used for calibrating the river network model. Hence, the S3B station at $x=779 \mathrm{~km}$ on the Rio Negro is selected. At this S3B station, the calibrated hydraulic model reproduces quite well the altimetric data not included in the calibration dataset of the river network model (see Fig. 5d).

These four stations are the one represented on Fig. 5.

\subsubsection{SFD extrapolation scenarii}

Scenarii are proposed here to test the influence of the time windows corresponding to S3A or J3 data (river network

model calibration period), and next S3B, on the resulting SFD parameters and discharge extrapolation capability in time: 
- (T1) a first time window (one year period) after the hydraulic model calibration (the 117 first days, see Sec. 3.2 and the black bars on Figs. 8 and 9);

- $(T 2-A)$ a second time window after the first one above to test the calibrated SFD laws with the remaining altimetric data at S3A or J3 VS;

- (T2-B) last, a time window corresponding to the use of previously calibrated SFD laws but with a new S3B altimetric VS, not used for model construction and calibration, hence representing a spatial extrapolation scenario.

\subsection{Results} method detailed in Sec. 2.3.2 and Sec. 3.3 over the experiments described in Sec. 4.1. First, the calibration of SFD laws is investigated in terms of discharge estimation efficiency, and then regarding the inferred values of SFD parameters. The estimates of the discharge are compared to the reference one from the calibrated river network model at the four stations of interest using metrics described in Sec. A (see Figs. 8 and 9), as well as the hydraulic

\subsubsection{Performance of discharge SFD}

The comparison of the estimated discharge time series with uncertainties (see Figs. 8 and 9) and the related scores (see Tab. 3) shows overall good discharge estimates for the 4 virtual stations. The NSE (Nash-Sutcliffe Efficiency coefficient) obtained with the different SFD sets is of the order of 0.9 or more. Moreover, considering the WS slope $\sigma_{1}$ and $\sigma_{2}$ (see Sec. 2.3.2) imply that the estimated discharge uncertainties are larger for higher discharges. Note that unsurprisingly, the discharge estimated with the calibrated Low Froude model based on river network model outputs (including unobservable water depth and hydraulic radius) gives nearly perfect discharges in the present case.

For each virtual station considered, the SFD performances remain comparable for the successive time windows considered in our experiments, including temporal extrapolation at S3B station. Performance decrease can be noted around $t=1200$ days for the VS on the Rio Branco station at $x=736 \mathrm{~km}$, with underestimates of high discharges (see Fig. 8c). The RMSNE (Root Mean Square Normalized Error) ranges between 24 and $29 \%$ and be attributable to the misfit between river network model and altimetric data (see Fig. 5c) as highlighted by the nearly perfect discharge estimate obtained with the low Froude model and river network model outputs only (red points on Fig. 8c). The misfit between altimetric $Z_{o b s}$ and simulated $Z_{s w}$ (see analysis in Sec. 3.3.1) seems more important at low flows. Given the higher number of observations points at low flows, this misfit impacts the SFD standard deviation: $\sigma_{1}$ is rather high (in comparison to other SFD obtained), $\sigma_{2}$ is negligible, which coupled with the wide range of discharges implies larger uncertainty envelops for high discharge.

The benefit of considering the WS slopes in the SFD is highlighted for each of the 4 stations in terms of dis615 charge performance, fine scale $S_{f s}$ and large scale $S_{l s}$ slopes or no slope - i.e. a SD law - (see Figs. 8 and 9). At the station downstream of the Rio Negro $(x=250 \mathrm{~km}$, see Figs. 8a and 5a), the NSE and RMSNE (see Tab. 3) for the different SFD laws show that using the slopes computed with the river network model improves the discharge 
estimation: the NSE is greater than 0.99 and the RMSNE less than 2.5\% when the fine and large scale slopes are used. On the other hand, the NSE is around 0.826 and the RMSNE is around $9 \%$ without slope (i.e. with $\delta=0$ ).

\subsubsection{Analysis of the SFD coefficients}

The computed SFD coefficients are presented in Tab. 3 and analyzed against the reference ones from the low Froude equation (4). When the fine scale $S_{f s}$ or large scale $S_{l s}$ slopes are used, and except on the Rio Branco station, the estimated SFD coefficients, especially $\gamma, \delta$ and $b_{s f d}$, are rather close from the corresponding values in reference bathymetry for the effective bathymetry elevation $b_{s f d}$ (for the reference low Froude $b_{s f d}=z_{b}$, with $z_{b}$ the bathymetry of the river network model).

Moreover, when the slope is considered noised or not, the value of $\alpha$ and $\delta$ are much lower. Since the slope is less accurate, the value of $\delta$ is lower (or 0 if no slope is considered). Because of the magnitude of the slope (between of $\alpha$ can be retrieved in Mansanarez et al. [2016] between the SD and SFD relationships. In our cases, $b_{s f d}$ and $\gamma$ also vary and compensations with other parameters exist.

Considering the VS on the Rio Branco, the coefficients are rather different from the trends analyzed above. When $\eta=\left(\alpha, \delta, \gamma, b_{s f d}\right)$ (i.e. a slope estimation is considered with a free exponent $\delta$ ), the estimated $\delta$ is nearly equal to 1 and the coefficient $\alpha$ becomes large. The coefficient $\delta$ is constrained between 0 and 1 (see Sec. 2.3.2) to avoid large non-physical values - we find $\delta \approx 4$ when using unconstrained minimization.

As mentioned previously, at this station, the misfit between $Z^{o b s}$ and $Z_{s w}$ is significant at low flows and impacts the calibration of SFD coefficients. Note also the the variations in time of the WS slope that are nearly correlated to the variations in time of the WSE. Using altimetric WSE $Z^{o b s}$ and simulated slopes and discharges results in rather low $\gamma$ values, compared to those at other VS. This calibration compensates the misfit between the observed and the river network model WSE with the slope that is consistent with model discharges $Q_{s w}$. This compensation implies this high coefficient $\delta$.

This trend is confirmed by the SD law (with $\delta=0$ ) that provides more physical coefficients - even though the NSE and the RMSNE are not as good as for the other stations: the noisy WSE observations can not be compensated by the slope in such case. This is also supported by the very close $K$ values of both the calibrated river network and 
reference low Froude models.

For the SFD with $\delta=0.5$, the coefficient $\alpha$ is always either rather low with high value of $\gamma$ and of $b_{s f d}$, or rather high with low value of $\gamma$ and of $b_{s f d}$. It can be explained by the fact that a deterministic algorithm is used with the only constraint that $\alpha, \beta, \delta, \gamma$ must not be negative. Without more constraint, the coefficients compensate each other. If some more restrictive constraints near the physical values are added (even just on one coefficient), then these physical values are nearly retrieved and the performance are almost the same. This is further studied in Discussion section.

670 Overall, the coefficients of the SFD laws obtained with our method are rather consistent with the coefficients given by the low Froude law (4) under the wide rectangular cross-section assumption. Some compensations appear in case of poor constraint on SFD parameters and/or of noisy altimetric observations. In Mansanarez et al. [2016], the coefficients of the SFD laws obtained are closer to the coefficients given by the low Froude law (4) than ours. This comes from the fact that their prior estimations are based on in situ measurements of known accuracy. Hence, 675 they can estimate more constraining standard deviations. On the other hand, the satellite data does not provide such estimations and the standard deviations of the prior distributions are larger (see Sec. 2.3.2). Hence, the coefficients of our SFD laws tend to deviate more from the coefficients of the low Froude law in comparison of the coefficients found in Mansanarez et al. [2016]. 

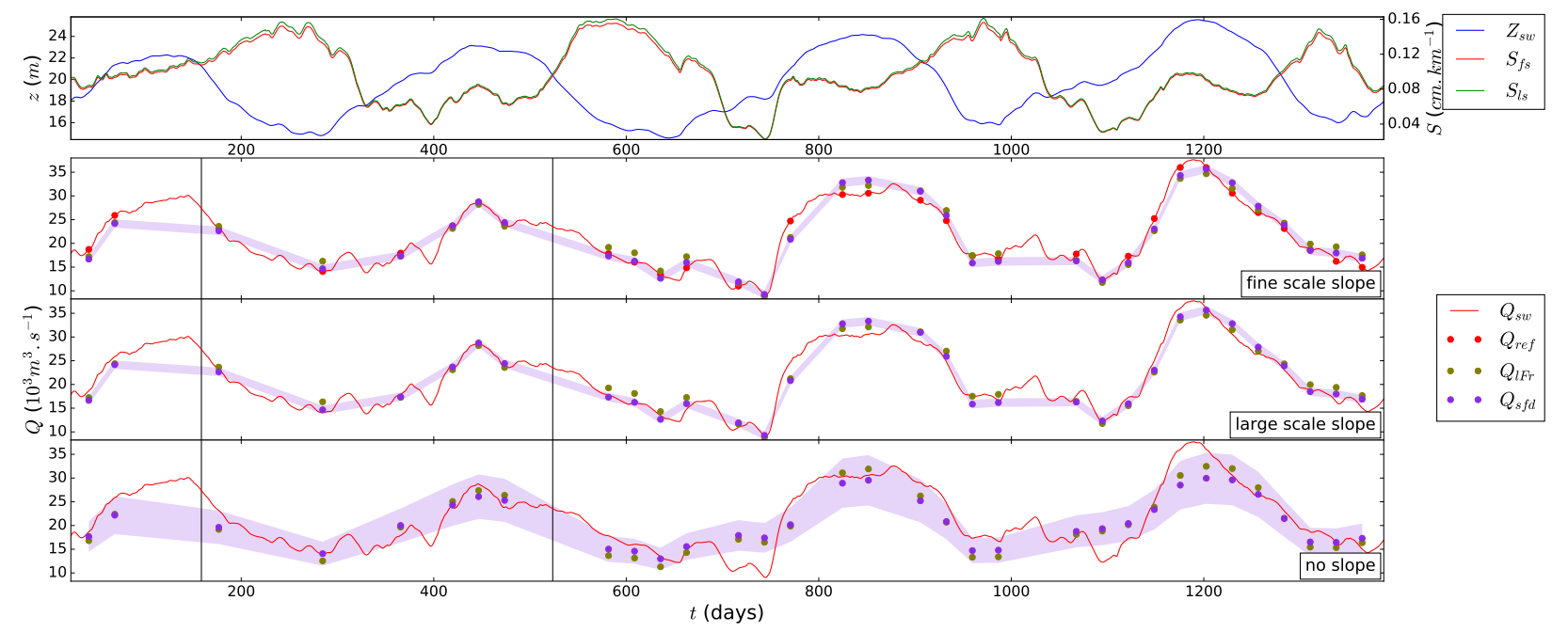

(a) $x=250 \mathrm{~km}$, Rio Negro (S3A VS).

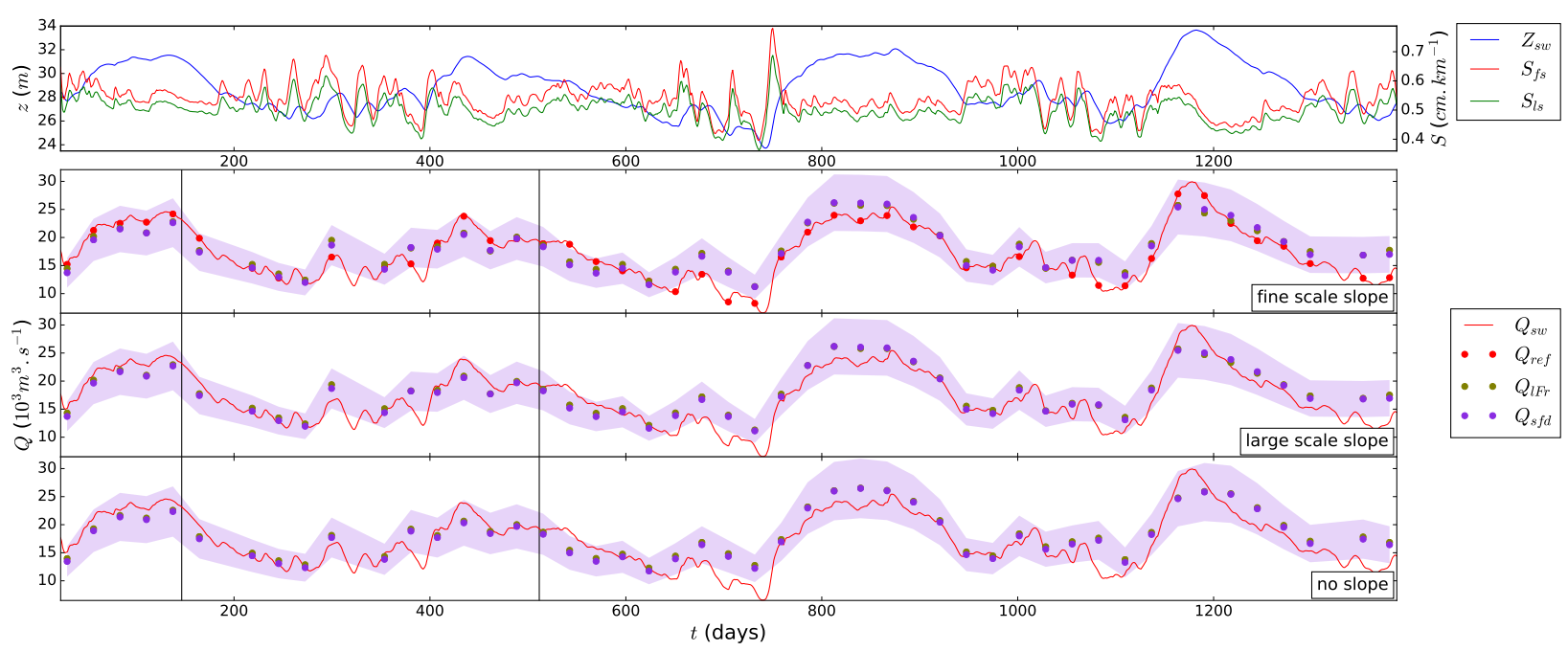

(b) $x=612 \mathrm{~km}$, Rio Negro (S3A VS).

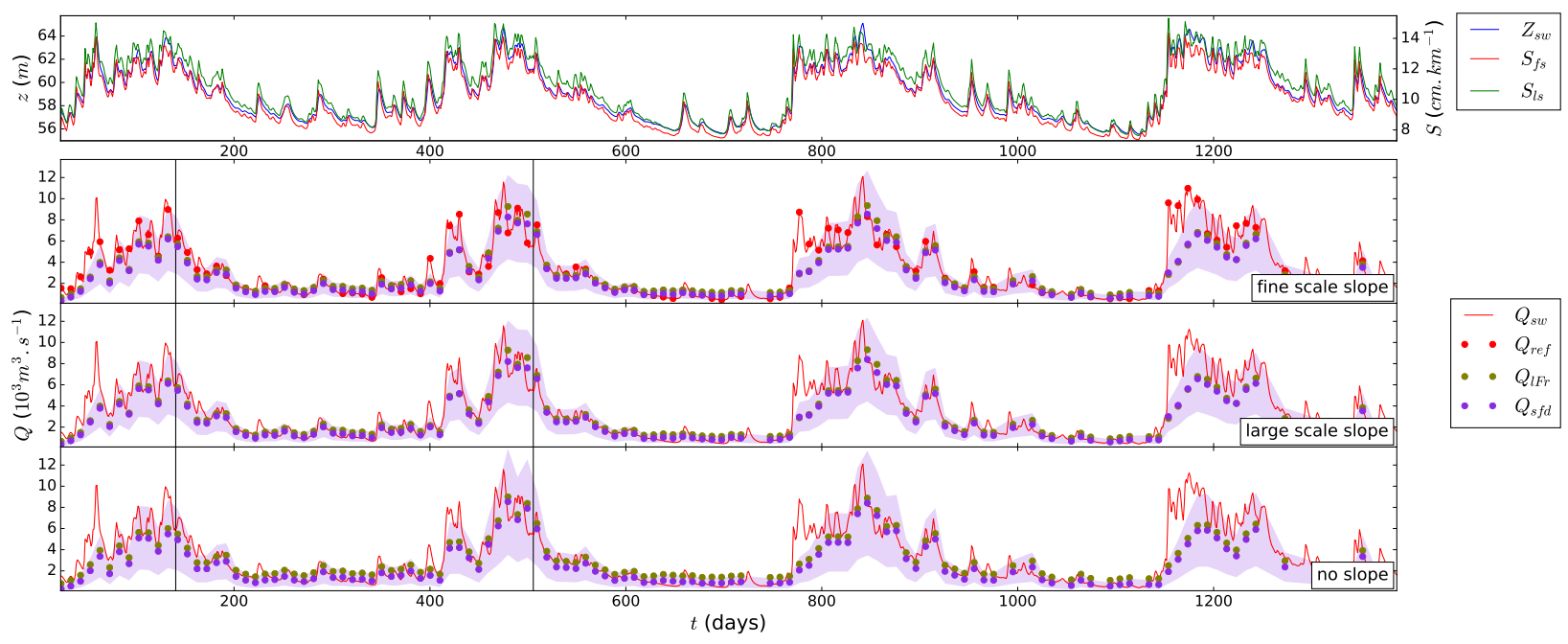

(c) $x=736 \mathrm{~km}$, Rio Branco (J3 VS).

Figure 8 - Simulated time series of hydraulic variables and discharges inferred from SFD and J3 or S3A altimetric data at the VS of interest using multi-scale WS slopes (fine and SWOT reach scales, see Sec. 3.3.2). Comparison to reference discharge $Q_{\text {ref }}$ given by the low Froude model and "true" discharge of the river network model $Q_{s w}$. The red envelops correspond to $95 \%$ uncertainty intervals computed from the distribution given by the MCMC algorithm. Vertical black lines delimit the calibration time window for the SFD laws and low Froude model. 


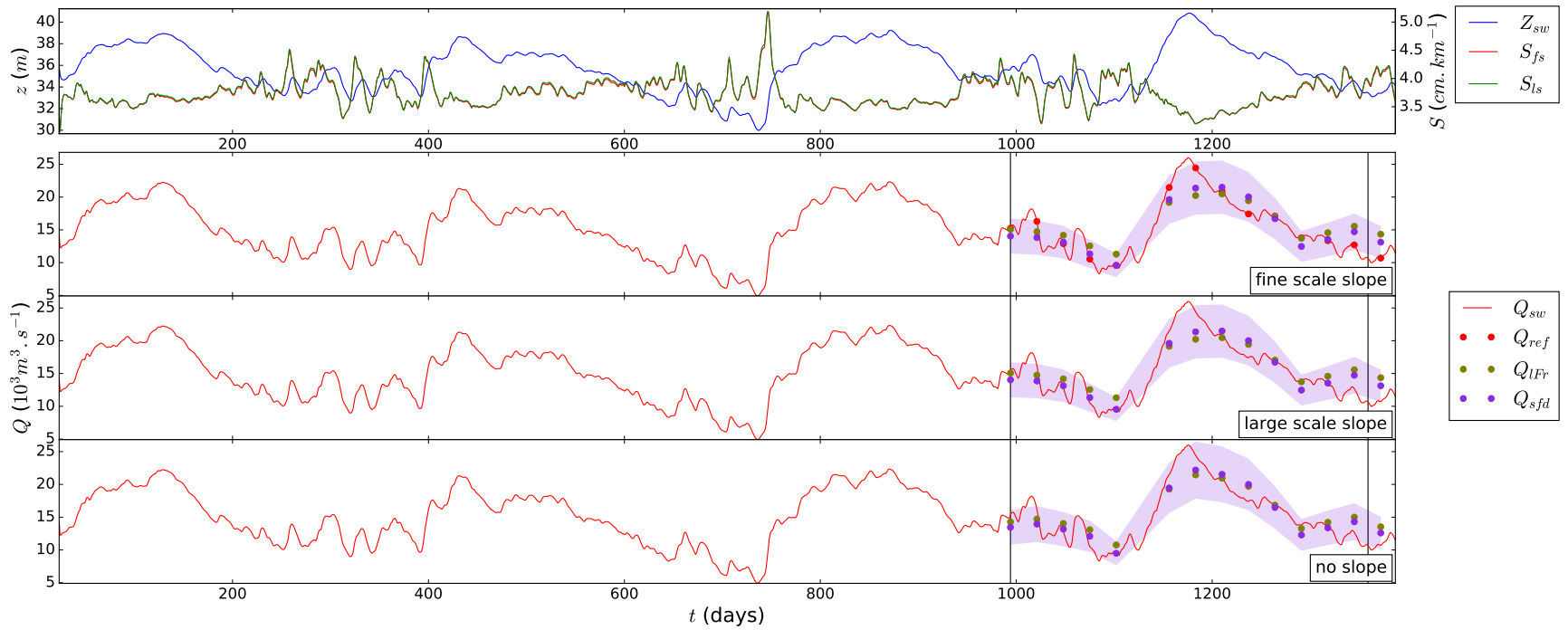

Figure 9 - Simulated time series of hydraulic variables and discharges inferred from SFD and altimetric data at S3B VS on the Rio Negro at $x=779 \mathrm{~km}$, using multi-scale WS slopes (fine and SWOT reach scales, see Sec. 3.3.2). Comparison to reference discharge $Q_{r e f}$ given by the low Froude model and "true" discharge of the river network model $Q_{s w}$. The red envelops correspond to $95 \%$ uncertainty intervals computed from the distribution given by the MCMC algorithm. Vertical black lines delimit the calibration time window for the SFD laws and low Froude model. 


\begin{tabular}{|c|c|c|c|c|c|c|c|}
\hline & & $S_{f s}$ & $S_{l s}$ & $S_{l s, \sigma=0.1}$ & $\delta=0$ & $S_{f s}, \delta=0.5$ & low Froude ref \\
\hline \multirow{8}{*}{$\begin{array}{l}\text { Rio Negro } \\
x=250 \mathrm{~km}\end{array}$} & $\alpha$ & 18.94 & 17.71 & 0.18 & 0.06 & 524.73 & 39.35 \\
\hline & $\gamma$ & 1.67 & 1.68 & 1.21 & 1.45 & 0.96 & $5 / 3$ \\
\hline & $\delta$ & 0.44 & 0.43 & 0.03 & 0 & 0.5 & 0.5 \\
\hline & $b_{s f d}(m)$ & 5.47 & 5.48 & 4.06 & 2.48 & 11.44 & 3.98 \\
\hline & $\sigma_{1}$ & $2.6 \times 10^{-5}$ & $1.63 \times 10^{-9}$ & $4.37 \times 10^{-9}$ & $8.99 \times 10^{-2}$ & & \\
\hline & $\sigma_{2}$ & $4.44 \times 10^{2}$ & $4.47 \times 10^{2}$ & $1.96 \times 10^{3}$ & $7.22 \times 10^{-46}$ & & \\
\hline & $N S E_{Q_{s f d}}$ & 0.99 & 0.99 & 0.83 & 0.81 & $\approx 1$ & $\approx 1$ \\
\hline & $R M S N E_{Q_{s f d}}$ & $2.48 \%$ & $2.49 \%$ & $8.49 \%$ & $8.99 \%$ & $1.69 \%$ & $0.32 \%$ \\
\hline \multirow{8}{*}{$\begin{array}{l}\text { Rio Negro } \\
x=612 \mathrm{~km}\end{array}$} & $\alpha$ & 3.87 & 7.09 & 0.02 & 0.06 & 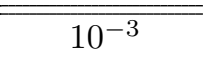 & 29.54 \\
\hline & $\gamma$ & 1.63 & 1.66 & 2.11 & 1.68 & 4.5 & $5 / 3$ \\
\hline & $\delta$ & 0.32 & 0.38 & 0.01 & 0 & 0.5 & 0.5 \\
\hline & $b_{s f d}(m)$ & 17.68 & 17.38 & 15.03 & 17.09 & 0.87 & 16.53 \\
\hline & $\sigma_{1}$ & $9.62 \times 10^{-2}$ & $9.56 \times 10^{-2}$ & $1.75 \times 10^{-11}$ & $\times 10^{-1}$ & & \\
\hline & $\sigma_{2}$ & $3.25 \times 10^{-2}$ & $5.99 \times 10^{-3}$ & $1.75 \times 10^{3}$ & $1.06 \times 10^{-2}$ & & \\
\hline & $N S E_{Q_{s f d}}$ & 0.73 & 0.74 & 0.74 & 0.72 & 0.74 & $\approx 1$ \\
\hline & $R M S N E_{Q_{s f d}}$ & $9.62 \%$ & $9.56 \%$ & $10.29 \%$ & $10.03 \%$ & $9.19 \%$ & $0.24 \%$ \\
\hline \multirow{8}{*}{$\begin{array}{l}\text { Rio Branco } \\
x=736 \mathrm{~km}\end{array}$} & $\alpha$ & 4602.42 & 4412.12 & 2858.11 & 0.29 & 216.92 & 19.96 \\
\hline & $\gamma$ & 1.231 & 1.214 & 1.156 & 1.533 & 0.648 & $5 / 3$ \\
\hline & $\delta$ & 1.0 & 1.0 & 0.95 & 0 & 0.5 & 0.5 \\
\hline & $b_{s f d}(m)$ & 55.27 & 55.27 & 55.27 & 55.27 & 57.29 & 53.77 \\
\hline & $\sigma_{1}$ & $2.41 \times 10^{-1}$ & $2.37 \times 10^{-1}$ & $2.55 \times 10^{-1}$ & $2.94 \times 10^{-1}$ & & \\
\hline & $\sigma_{2}$ & $2.07 \times 10^{-27}$ & $5.37 \times 10^{-91}$ & $1.1 \times 10^{-32}$ & $5.9 \times 10^{-4}$ & & \\
\hline & $N S E_{Q_{s f d}}$ & 0.81 & 0.81 & 0.76 & 0.69 & 0.83 & $\approx 1$ \\
\hline & $R M S N E_{Q_{s f d}}$ & $24.12 \%$ & $23.67 \%$ & $25.51 \%$ & $29.42 \%$ & $33.36 \%$ & $0.16 \%$ \\
\hline \multirow{8}{*}{$\begin{array}{l}\text { Rio Negro } \\
x=779 \mathrm{~km}\end{array}$} & $\alpha$ & 4.14 & 6.14 & 0.01 & 0.03 & $10^{-3}$ & 13.04 \\
\hline & $\gamma$ & 2.1 & 1.97 & 2.21 & 2 & 4.17 & $5 / 3$ \\
\hline & $\delta$ & 0.52 & 0.51 & $\approx 0.0$ & 0 & 0.5 & 0.5 \\
\hline & $b_{s f d}(m)$ & 24.71 & 25.57 & 22.99 & 24.46 & 11.8 & 24.12 \\
\hline & $\sigma_{1}$ & $9.47 \times 10^{-2}$ & $9.47 \times 10^{-2}$ & $9.86 \times 10^{-2}$ & $9.83 \times 10^{-2}$ & & \\
\hline & $\sigma_{2}$ & $2.21 \times 10^{-1}$ & $1.55 \times 10^{-1}$ & $8.01 \times 10^{-15}$ & 2.71 & & \\
\hline & $N S E_{Q_{s f d}}$ & 0.85 & 0.85 & 0.86 & 0.86 & 0.86 & $\approx 1$ \\
\hline & $R M S N E_{Q_{s f d}}$ & $9.47 \%$ & $9.47 \%$ & $9.86 \%$ & $9.85 \%$ & $9.4 \%$ & $0.06 \%$ \\
\hline
\end{tabular}

Table 3 - Coefficients and efficiency criteria (see Sec. A) obtained with SFD on the calibration time period at the $4 \mathrm{VS}$ of interest, in bold face the coefficients imposed by physical a priori (slope exponents $\delta$ ) or given by the reference low Froude model from river network model outputs (last column). In all cases, the width exponent $\beta=1$ (rectangular cross sections in the reference river network model).

\section{Discussions}

Having investigated the computation of SFD laws at virtual stations in contrasted hydraulic contexts, we discuss in this section the spatial variability of the SD coefficients, estimation issues for real river bathymetry and also the use of dynamic water masks. Finally, we discuss the applicability of the method with the future SWOT data. 


\subsection{AMHG analysis of Negro-Branco SD coefficients}

In an attempt to relate river discharge to flow vein features, At-a-station Hydraulic Geometry (AHG) relationships were proposed in Leopold and Maddock [1953]. Using log linearization of hydraulic geometry expressed in water depth at different locations along a river gives the so-called AMHG [Gleason and Smith, 2014]:

$$
\frac{1}{\ln Q(x, t)} \ln (h(x, t))=\frac{1}{\ln Q(x, t)} \ln (c(x))+d(x)
$$

The SFD estimation has been investigated on the Negro-Branco River network representing a complex case, yet with rectangular cross-sections and channel flow controls (bathymetry-friction) defined at the virtual stations. A real complex river geometry is now considered in order to investigate SFD estimation in presence of fine scale hydraulic controls due to the complex river geometry including cross-sections of varying width. [2018] and references therein, constant friction in space). We study the SFD estimate considering hydraulic quantities simulated with a fine 1D hydraulic model (here equation (1)) built from the in situ Garonne data including bathymetric surveys (non-rectangular cross-sections, see top figure of Fig. 11) and gauging stations records. Note that the Froude number goes up to about 0.5 on the space-time domain which is higher than on the Negro-Branco

In Gleason and Smith [2014], the coefficients of the AHG relationships are computed over many stations (AMHG relationships) and a log-linear correlation of those coefficients is highlighted. This representation is applied to our discharge laws.

The AHG coefficients $c$ and $d$ of the AHG relation $h=c Q^{d}$ are obtained at all virtual stations on the NegroBranco River network from the outputs of the river network model using a linear least square algorithm. The linear trends between $\log (c)$ and $d$ from the AMHG analysis is then computed over the three main reaches (see Fig. 10), i.e. between the main flow variations upstream and downstream of the Negro-Branco confluence, using a linear least square algorithm.

In Paris et al. [2020], the hydraulic geometry $h=c Q^{d}$ is highlighted as equivalent to a SD relationship: assuming (5) with $\beta=0, \delta=0$ and $b_{s f d}=z_{b}$ then $\alpha=c^{-\frac{1}{d}}$ and $\gamma=\frac{1}{d}$. Once the relation established by AMHG between $c$ and $d$ (equation (12)) is computed over a reach, one can check that a newly added SD relationship satisfies the trend in order to validate the SD relation.

From this analysis, one can even spot the SD with problematic coefficients or lower quality: for example, the Rio Branco VS at $x=736 \mathrm{~km}$ provides lower quality SFD and SD laws (because of the misfit between the river network model and observed WSE, see Sec. 4.2) and is visible as the red square (the most right one) on 10 (rather far from the blue line).

However, this AHG relationship is a power law between $h$ and $Q$. Hence, the resulting estimation of the discharge will not take into account the effect of the slope, which is crucial when the flow is affected by backwater effect. Moreover, it implies the bathymetry is needed to estimate $h$ from the satellite observation. At last, computing the coefficients of a local AHG relationship from an already existing AMHG relationship is difficult. As a matter of fact, a simple way to infer a priori values for AHG coefficients is highlighted in Paris et al. [2020]. However, the uncertainties behind turns it almost impossible to generalize with no prior information.

The AMHG method represents an interesting analysis tool of the SD laws coherence.

\subsection{Influence of hydraulic controls and water masks on SFD}

River. The SFD are calibrated with a deterministic algorithm (same as presented in Sec. 4.1.1) applied to the 


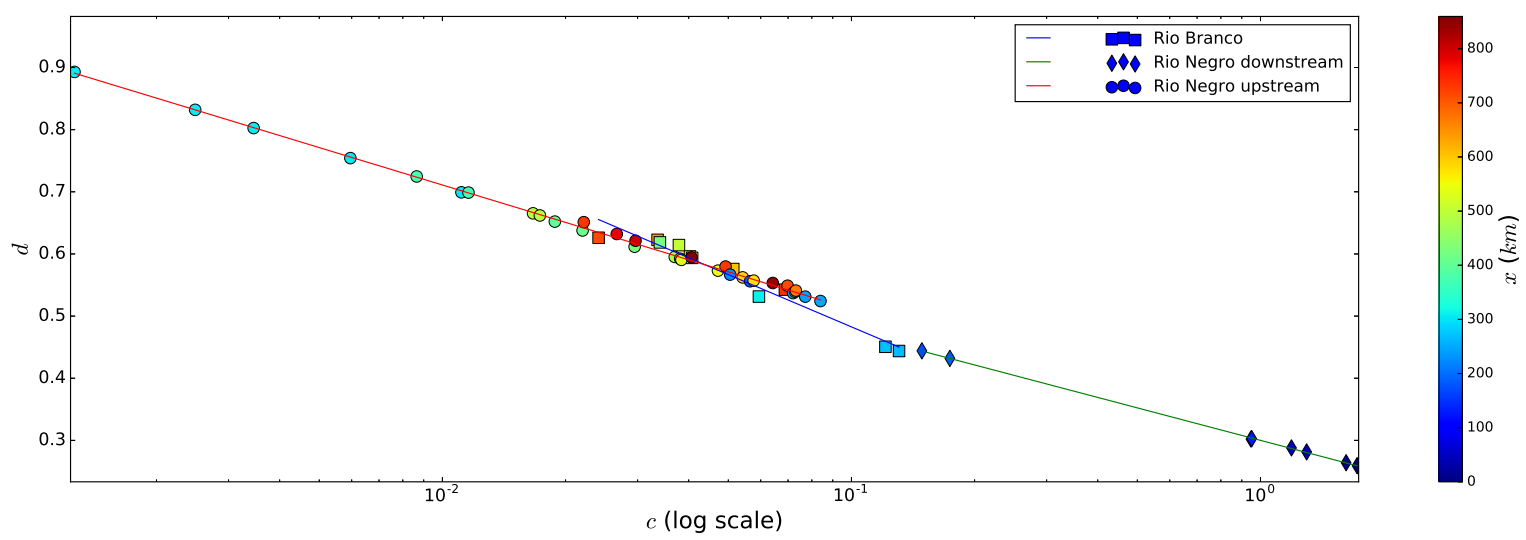

Figure 10 - AMHG relationship applied to the outputs of the calibrated hydraulic model on the full Negro-Branco river network over the whole simulation time window, $c$ vs $d$ in the AMHG relationship for the simulated $h-Q$ hydraulic geometry.

parameter set $\eta=\left\{\alpha, \beta, \gamma, b_{s f d}\right\}$ with $\delta=0.5$ and using $Z, S, Q$ and $W$ from the river flow model (on the whole time period). In order to avoid non-physical coefficient values because of compensations, we bound the coefficient $\gamma \in[0 ; 10 / 3]$. The impact of considering width data or not is tested by setting $\beta \neq 0$ or $\beta=0$.

The resulting SFD laws are accurate: overall the NSE is greater than 0.95 and the $R M S N E$ is less than $7 \%$. For only two reaches, less accurate SFD are found (around $x=19 \mathrm{~km}$ and $x=24 \mathrm{~km}$ ) corresponding to issues related to sudden overbank bathymetry enlargements - floodplain flows are not in the scope of this study.

The fine scale spatial variability obtained for the SFD coefficients (see Fig. 11) shows limited compensations, and stems from the succession of rifle and pools reflected in both WSE and (fine scale) slopes signatures used for SFD calibrations.

The effective bathymetry determined that way is fairly good ( $R M S E$, Root Mean Square Error, between $b_{s f d}$ and $b$ is around $1 m$, see Fig. 12). For similar discharge efficiencies, the riffle and pools are correctly retrieved in effective bottom elevation $b_{s f d}$ only when the slope exponent is $\delta=0.5$ (see zoom on top figure of Fig. 12). In that case ( $\delta=0.5$ ), but when $\eta=\left\{\alpha, \gamma, b_{s f d}\right\}$ (with or without width, i.e. $\beta \neq 0$ or $\beta=0$ ) the pools bottom elevations are underestimated. The effective bottom elevation is retrieved with better accuracy, including pools, when the SFD law free parameters are $\eta=\left\{\alpha, b_{s f d}\right\}$ and using the $\delta=0.5, \gamma=5 / 3$ as in the Manning-Strickler equation, setting $\beta=0$ for the width. Hence, compensations between SFD parameters are reduced when using hydraulic meaningful values.

Moreover, using SFD laws estimated without width data, i.e. $\beta=0$, results in comparable discharge estimation efficiencies: overall the RMSNE and NSE are respectively less than $7 \%$ and greater than 0.95 . It shows that considering width time series do not improve SFD performance in estimating discharge and effective bottom elevation. However, considering WS slope time series reveals to be crucial. Indeed, WS slope represents a fine hydraulic signature containing both at a section and longitudinal channel-flow signatures. This highlights how valuable is a river network hydraulic model for combining multi-source data including WSE and water masks to reproduce nonlinear flow signatures arising from spatio-temporal combinations of flow controls with various influence length (along and against flow direction).

The ability of a flow model to simulate accurate WS signatures and especially meaningful slopes pertains to the 


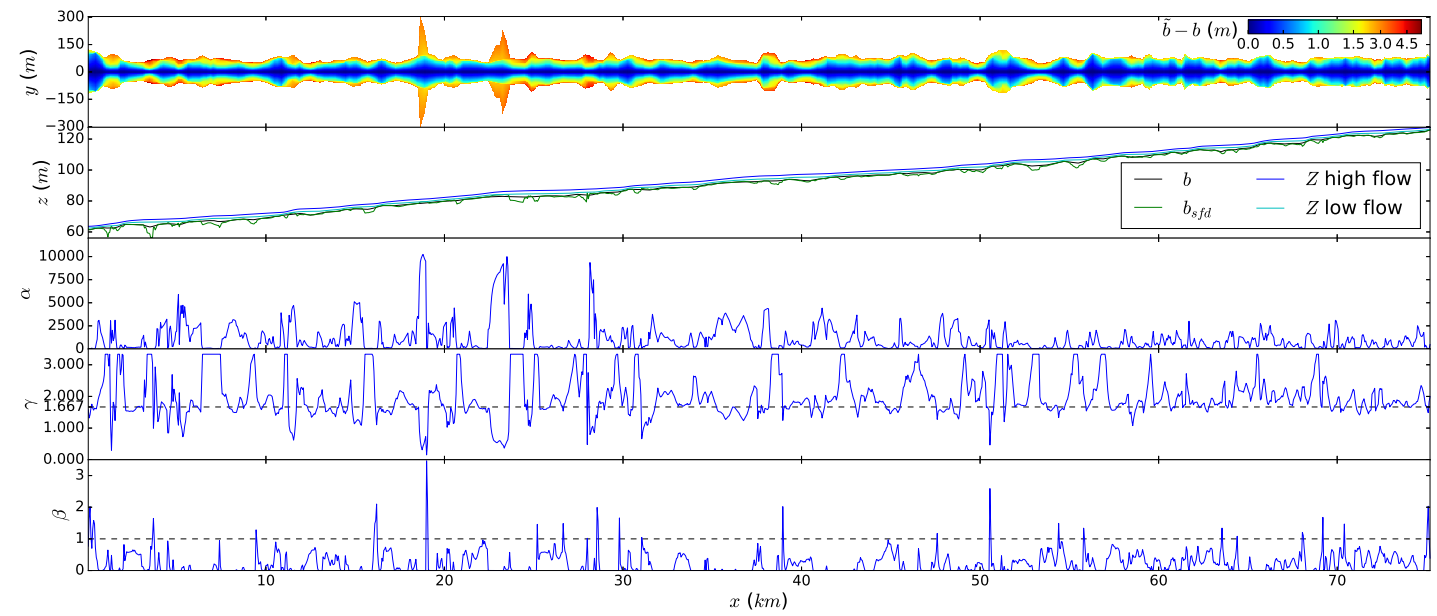

Figure 11 - Deterministic SFD calculated on the fine scale Garonne River case downstream of Toulouse, France, based on reference hydraulic model built on detailed bathymetry from in situ surveys (width profile on top panel in flow cross sectional direction $y$ ). Spatial variations of river channel geometry (effective bottom elevation $b$ and inferred one $\tilde{b})$ and of the coefficients $\alpha, \gamma, b_{s f d}$ of the SFD law $(\delta=0.5$ and $\gamma \in[0,10 / 3])$. The dashed lines are the values given by the low Froude equation (4) under the rectangular cross-section assumption.

representation of hydraulic controls. In the case of the Negro-Branco River network model, the segmentation of the river is based on the grid imposed by the relatively sparse spatial sampling of altimetric VS. Hence, the question of the accuracy of the space extrapolation (illustrated over the S3B station in Sec. 4.2) is related to the question of the hydraulic controls represented by this segmentation.

The impact of river segmentation on simulated flow signatures including slope is investigated in Montazem et al. [2019] on the reach of the Garonne and also of the Negro River studied here. The authors proposed a segmentation strategy preserving hydraulic signal. This strategy could be used for tayloring river models, at different scales depending on river network morphological features, in future works for example using the forthcoming SWOT observations of rivers profiles worldwide.

Note that physically sound representations of river networks flows signatures can also be obtained while assimilating noisy SWOT-like data using DassFlow-1D hydraulic model (e.g. Brisset et al. [2018], Garambois et al. [2020a], Larnier et al. [2020], Pujol et al. [2020], Tuozzolo et al. [2019]). Therefore the present method for estimating SFD laws would also be applicable in that case.

Regarding operational applications, such network models fusing the available information represent pertinent analysis tools and enable to calibrate SFD laws. These SFD laws provide discharge estimations using the simulated WS slopes given hydrological forcings. The computation time needed to run MGB on the full window is around 20 minutes, and the update with new forcings takes about 30 seconds. The computation time needed to run the DassFlow river network model over the Negro-Branco river network is about 40 seconds for a one year time period and about 150 seconds for the whole time window presented in Sec. 3.1. Hence this method can provide (near-)real time discharge estimation as long as the forcing is available as well as altimetry data. 


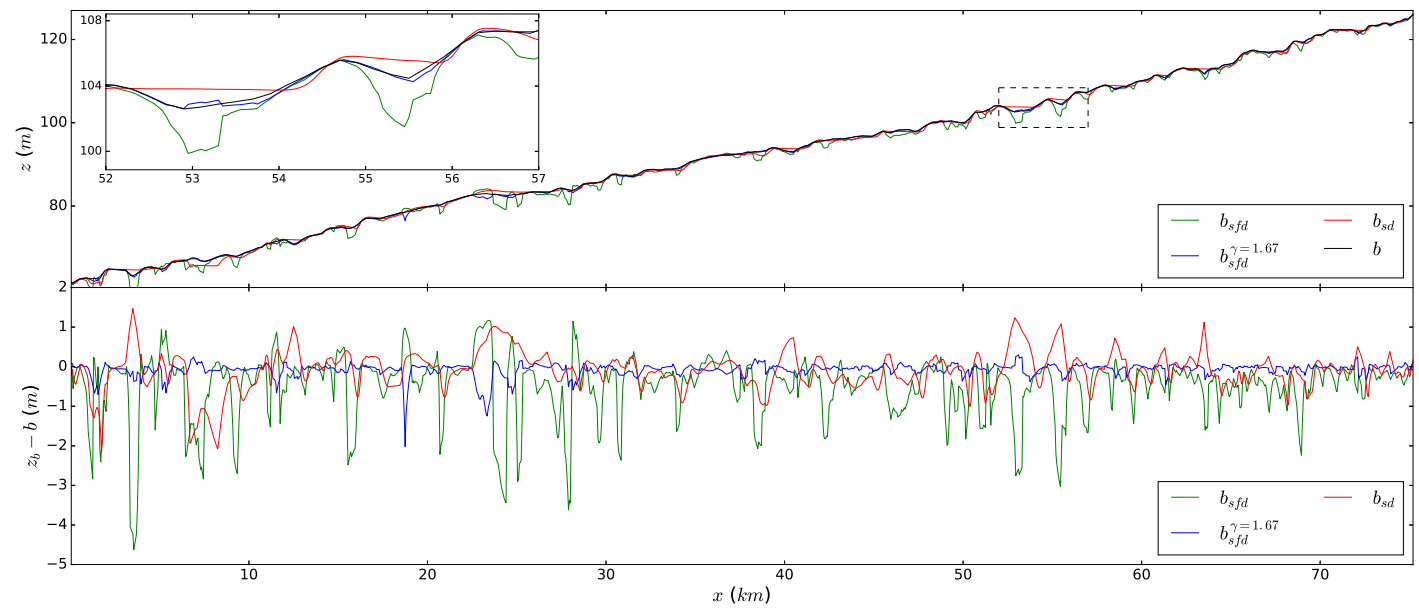

Figure 12 - Estimations of river channel bottom elevation using different SFD laws (5) with deterministic calibration of their parameter set $\eta=(\alpha, \beta, \gamma, \delta)$ for each river cross section using reference hydraulic outputs of the Garonne River model: $s d$ denotes the standard SD law $\left(\beta=0\right.$ and $\left.\delta=0, R M S E_{b}=0.24 m\right)$, sfd denotes the full SFD law with $\delta=0.5$ and $\beta=0\left(R M S E_{b}=0.85 \mathrm{~m}\right), \underset{s f d}{\gamma=1.67}$ denotes a full SFD law with $\delta=0.5, \gamma=5 / 3$ and $\beta=0\left(R M S E_{b}=0.03 m\right)$ that is the exponents of the Low Froude model (Manning equation (4) using WS slope). The obtained river bottom elevations are compared to the one of the 1D hydraulic model obtained from in situ bathymetry surveys.

\section{Conclusion}

This paper proposed a methodology to derive stage-fall-discharge laws aimed at operational discharge estimates at any point of a hydrographic network. Moreover, this method is amenable to reaches affected by variable friction slope, hence affected by stage-discharge hysteresis. This methodology takes advantage of meaningful hydraulic signatures simulated with a river network hydraulic model in coherence with multi-satellite data. The estimation of the discharge is provided by SFD laws calibrated with discharges from the river network model and multi-mission satellite altimetry data enabling operational estimation.

A coupling between the river network hydraulic model DassFlow-1D [Brisset et al., 2018, Larnier et al., 2020] and the large scale hydrological model MGB [Collischonn et al., 2007] is performed (following Pujol et al. [2020]) to ensure hydrological consistency of water fluxes. It is applied in this paper on the Negro-Branco River network Amazon basin, a case with complex morphology and hydrodynamics [Pujol et al., 2020], using a rich multi-satellite dataset. The effective hydraulic model built from optical water masks is put in coherence with multi-mission altimetric data (Jason-3 and Sentinel-3A and -3B measurements between February 2016 to May 2019) through a variational calibration of spatially distributed friction patches (see Garambois et al. [2020b]). The obtained river network model fits the WSE on the calibration-validation period with a satisfying median accuracy of $53 \mathrm{~cm}(80 \%$ elevations below $\pm 1 m$ fit at observation times, similar height error reported e.g. in Silva et al. [2010]) in space and time regarding potential altimetric uncertainties along with those from hydrological fluxes and effective channel bathymetry-friction on this ungauged basin. By means of data assimilation, given the noisy altimetric dataset and our modeling hypothesis, an optimal numerical representation of river network WS signatures is obtained on the segmentation imposed by altimetric spatial sampling in the present case. Such a model enables to extrapolate fine scale reference discharges and WS slopes over the whole space-time domain which remains difficult from sparse 

in a SWOT context. The present method could also be applied to $2 \mathrm{D}$ hydraulic models in coherence with multisource datasets.

\section{Author contributions}

825 This work is part of the PhD thesis work of TM (CIFRE PhD 2018/0725, funded by ANRT). Research and experimental plan: PAG, TM, JM. Data curation: TM, AP. DassFlow network solver upgrade: KL. Numerical experiments: TM. Analysis: TM, PAG, JM, AP. Writing: all.

\section{A Performance evaluation metrics}

In order to evaluate the performance of the different estimates of $Q$, we define 4 criteria. The first is the Nash-Sutcliff 830 efficiency coefficient :

$$
N S E_{Q}=1-\sum \frac{\left(Q-Q_{s w}\right)^{2}}{\left(\bar{Q}_{s w}-Q_{s w}\right)^{2}}
$$


The second is the Root Mean Square Error $\left[\mathrm{m}^{3} \cdot \mathrm{s}^{-1}\right]$ :

$$
R M S E_{Q}=\sqrt{\overline{\left(Q-Q_{s w}\right)^{2}}}
$$

And the third and fourth are the Normalized Root Mean Square Error :

$$
N R M S E_{Q}=\frac{\sqrt{\overline{\left(Q-Q_{s w}\right)^{2}}}}{\bar{Q}_{s w}}
$$

and the Root Mean Square Normalized Error :

$$
R M S N E_{Q}=\sqrt{\overline{\left(\frac{Q}{Q_{s w}}-1\right)^{2}}}
$$

\section{B Performance evaluation on the stations}

\begin{tabular}{|l|c|c|c|c|c|}
\hline & $S_{f s}$ & $S_{l s}$ & $S_{l s, \sigma=0.1}$ & $\delta=0$ & low Froude ref \\
\hline \hline$W(m)$ & \multicolumn{5}{|c|}{5853.708} \\
\hline$z_{b}(m)$ & \multicolumn{5}{|c|}{3.979} \\
\hline$K_{s w}$ & \multicolumn{5}{|c|}{39.677} \\
\hline$K_{l F r}$ & 40.378 & 39.966 & 8.135 & 0.036 & 39.348 \\
\hline$\alpha$ & 18.943 & 17.709 & 0.184 & 0.057 & \\
\hline$\gamma$ & 1.668 & 1.676 & 1.212 & 1.451 & \\
\hline$\delta$ & 0.435 & 0.433 & 0.031 & 0.5 & \\
\hline$b_{s f d}(m)$ & 5.468 & 5.479 & 4.062 & 2.479 & \\
\hline$\sigma_{1}$ & $\approx 0.0$ & $\approx 0.0$ & $\approx 0.0$ & 0.09 & \\
\hline$\sigma_{2}$ & 444.306 & 447.079 & 1959.641 & $\approx 0.0$ & \\
\hline$N S E_{Q_{r c}}\left(m^{3} . s^{-1}\right)$ & $444.8(1515)$ & $446.8(1531)$ & $1960(3698)$ & $2071(3492)$ & \\
\hline$R M S E_{Q_{r c}}$ & $2.029 \%(7.082 \%)$ & $2.039 \%(7.154 \%)$ & $8.941 \%(17.28 \%)$ & $9.448 \%(16.32 \%)$ & \\
\hline$N R M S E_{Q_{r c}}$ & $2.481 \%(6.832 \%)$ & $2.487 \%(6.898 \%)$ & $8.485 \%(25.3 \%)$ & $8.987 \%(24.23 \%)$ & \\
\hline$R M S N E_{Q_{r c}}$ & $0.954(0.942)$ & $0.949(0.939)$ & $-1.28(-1.031)$ & $0.769(0.775)$ & \\
\hline$N S E_{Q_{l F r}}$ & $1008(1676)$ & $1056(1716)$ & $7084(9933)$ & $2255(3309)$ & $74.93(62.72)$ \\
\hline$R M S E_{Q_{l F r}}\left(m^{3} . s^{-1}\right)$ & $4.601 \%(7.834 \%)$ & $4.818 \%(8.02 \%)$ & $32.32 \%(46.42 \%)$ & $10.29 \%(15.47 \%)$ & $0.342 \%(0.293 \%)$ \\
\hline$N R M S E_{Q_{l F r}}$ & $6.687 \%(8.64 \%)$ & $6.973 \%(8.88 \%)$ & $35.68 \%(42.79 \%)$ & $10.49 \%(22.98 \%)$ & $0.32 \%(0.264 \%)$ \\
\hline$R M S N E_{Q_{l F r}}$ & & & &
\end{tabular}

Table 4 - Coefficients and efficiency criteria (see Sec. A) on both the calibration and validation (in parenthesis) time window for SFD and low Froude laws for the virtual station downstream of the Rio Negro $(x=250 \mathrm{~km})$. 


\begin{tabular}{|l|c|c|c|c|c|}
\hline & $S_{f s}$ & $S_{l s}$ & $S_{l s, \sigma=0.1}$ & $\delta=0$ & low Froude ref \\
\hline \hline$W(m)$ & \multicolumn{5}{|c|}{3844.449} \\
\hline$z_{b}(m)$ & \multicolumn{5}{|c|}{16.53} \\
\hline$K_{s w}$ & \multicolumn{5}{|c|}{29.219} \\
\hline$K_{l F r}$ & 26.932 & 27.974 & 16.055 & 0.063 & 29.538 \\
\hline$\alpha$ & 3.87 & 7.094 & 0.017 & 0.063 & \\
\hline$\gamma$ & 1.631 & 1.658 & 2.108 & 1.68 & 0.5 \\
\hline$\delta$ & 0.322 & 0.379 & 0.006 & 17.089 & \\
\hline$b_{s f d}(m)$ & 17.679 & 17.382 & 15.03 & 0.1 & \\
\hline$\sigma_{1}$ & 0.096 & 0.096 & $\approx 0.0$ & 0.011 & \\
\hline$\sigma_{2}$ & 0.033 & 0.006 & 1752.623 & $0.718(0.724)$ & \\
\hline$N S E_{Q_{r c}}\left(m^{3} . s^{-1}\right)$ & $1777(2275)$ & $1764(2234)$ & $1753(2775)$ & $1818(2510)$ & \\
\hline$R M S E_{Q_{r c}}$ & $10.41 \%(13.09 \%)$ & $10.32 \%(12.85 \%)$ & $10.26 \%(15.97 \%)$ & $10.64 \%(14.44 \%)$ & \\
\hline$N R M S E_{Q_{r c}}$ & $9.616 \%(17.44 \%)$ & $9.563 \%(17.09 \%)$ & $10.29 \%(20.89 \%)$ & $10.03 \%(19.53 \%)$ & \\
\hline$R M S N E_{Q_{r c}}$ & $0.718(0.767)$ & $0.732(0.771)$ & $-2.324(-1.174)$ & $0.725(0.694)$ & \\
\hline$N S E_{Q_{l F r}}$ & $1817(2310)$ & $1772(2288)$ & $6243(7052)$ & $1795(70522645)$ & $38.11(48.91)$ \\
\hline$R M S E_{Q_{l F r}}\left(m^{3} . s^{-1}\right)$ & $10.64 \%(13.29 \%)$ & $10.38 \%(13.17 \%)$ & $36.55 \%(40.58 \%)$ & $10.51 \%(15.22 \%)$ & $0.223 \%(0.281 \%)$ \\
\hline$N R M S E_{Q_{l F r}}$ & $10.18 \%(18.15 \%)$ & $9.994 \%(17.99 \%)$ & $41.09 \%(44.79 \%)$ & $10.42 \%(21.23 \%)$ & $0.246 \%(0.285 \%)$ \\
\hline$R M S N E_{Q_{l F r}}$ & & & &
\end{tabular}

Table 5 - Coefficients and efficiency criteria (see Sec. A) on both the calibration and validation (in parenthesis) time window for SFD and low Froude laws for the virtual station downstream of the Rio Negro $(x=612 \mathrm{~km})$.

\begin{tabular}{|c|c|c|c|c|c|}
\hline & $S_{f s}$ & $S_{l s}$ & $S_{l s, \sigma=0.1}$ & $\delta=0$ & low Froude ref \\
\hline$W(m)$ & \multicolumn{5}{|c|}{926.0429} \\
\hline$z_{b}(m)$ & \multicolumn{5}{|c|}{53.774} \\
\hline$K_{s w}$ & \multicolumn{5}{|c|}{20.028} \\
\hline$K_{l F r}$ & 16.813 & 16.21 & 15.525 & 0.178 & 19.955 \\
\hline$\alpha$ & 4602.418 & 4412.119 & 2858.112 & 0.287 & \\
\hline$\gamma$ & 1.231 & 1.214 & 1.156 & 1.533 & \\
\hline$\delta$ & 1.0 & 1.0 & 0.946 & 0.5 & \\
\hline$b_{s f d}(m)$ & 55.274 & 55.274 & 55.274 & 55.274 & \\
\hline$\sigma_{1}$ & 0.241 & 0.237 & 0.255 & 0.294 & \\
\hline$\sigma_{2}$ & $\approx 0.0$ & $\approx 0.0$ & $\approx 0.0$ & 0.001 & \\
\hline$N S E_{Q_{r c}}$ & $0.809(0.712)$ & $0.809(0.71)$ & $0.756(0.65)$ & $0.685(0.569)$ & \\
\hline$R M S E_{Q_{r c}}\left(m^{3} \cdot s^{-1}\right)$ & $1051(1487)$ & $1050(1492)$ & $1187(1640)$ & $1349(1819)$ & \\
\hline$N R M S E_{Q_{r c}}$ & $33.91 \%(42.38 \%)$ & $33.88 \%(42.52 \%)$ & $38.32 \%(46.74 \%)$ & $43.53 \%(51.85 \%)$ & \\
\hline$R M S N E_{Q_{r c}}$ & $24.12 \%(28.97 \%)$ & $23.67 \%(28.44 \%)$ & $25.51 \%(31.44 \%)$ & $29.42 \%(34.36 \%)$ & \\
\hline$N S E_{Q_{l F r}}$ & $0.778(0.71)$ & $0.777(0.709)$ & $0.744(0.675)$ & $0.729(0.66)$ & $\approx 1$ \\
\hline$R M S E_{Q_{l F r}}\left(m^{3} \cdot s^{-1}\right)$ & $1133(1492)$ & $1135(1496)$ & $1214(1580)$ & $1250(1616)$ & $9.281(18.94)$ \\
\hline$N R M S E_{Q_{l F r}}$ & $36.56 \%(42.54 \%)$ & $36.62 \%(42.63 \%)$ & $39.19 \%(45.04 \%)$ & $40.33 \%(46.07 \%)$ & $0.3 \%(0.54 \%)$ \\
\hline$R M S N E_{Q_{l F r}}$ & $34.7 \%(41.3 \%)$ & $34.14 \%(40.41 \%)$ & $31.37 \%(37.96 \%)$ & $46.78 \%(55.58 \%)$ & $0.152 \%(0.241 \%)$ \\
\hline
\end{tabular}

Table 6 - Coefficients and efficiency criteria (see Sec. A) on both the calibration and validation (in parenthesis) time window for SFD and low Froude laws for the virtual station downstream of the Rio Branco $(x=736 \mathrm{~km})$. 


\begin{tabular}{|c|c|c|c|c|c|}
\hline & $S_{f s}$ & $S_{l s}$ & $S_{l s, \sigma=0.1}$ & $\delta=0$ & low Froude ref \\
\hline$W(m)$ & \multicolumn{5}{|c|}{3170.011} \\
\hline$z_{b}(m)$ & \multicolumn{5}{|c|}{24.138} \\
\hline$K_{s w}$ & \multicolumn{5}{|c|}{20.028} \\
\hline$K_{l F r}$ & 10.491 & 10.471 & 10.204 & 0.063 & 13.035 \\
\hline$\alpha$ & 4.135 & 6.144 & 0.012 & 0.027 & \\
\hline$\gamma$ & 2.104 & 1.97 & 2.214 & 1.996 & \\
\hline$\delta$ & 0.517 & 0.509 & 0.0 & 0.5 & \\
\hline$b_{s f d}(m)$ & 24.714 & 25.569 & 22.991 & 24.46 & \\
\hline$\sigma_{1}$ & 0.095 & 0.095 & 0.099 & 0.098 & \\
\hline$\sigma_{2}$ & 0.221 & 0.155 & $\approx 0.0$ & 2.71 & \\
\hline$N S E_{Q_{r c}}$ & $0.852(0.845)$ & $0.852(0.844)$ & $0.859(0.86)$ & $0.859(0.86)$ & \\
\hline$R M S E_{Q_{r c}}\left(m^{3} \cdot s^{-1}\right)$ & $1622(1692)$ & $1622(1694)$ & $1584(1608)$ & $1585(1609)$ & \\
\hline$N R M S E_{Q_{r c}}$ & $10.25 \%(10.95 \%)$ & $10.25 \%(10.96 \%)$ & $10.01 \%(10.4 \%)$ & $10.02 \%(10.41 \%)$ & \\
\hline$R M S N E_{Q_{r c}}$ & $9.472 \%(10.96 \%)$ & $9.471 \%(10.97 \%)$ & $9.855 \%(10.6 \%)$ & $9.852 \%(10.61 \%)$ & \\
\hline$N S E_{Q_{l F r}}$ & $0.793(0.763)$ & $0.792(0.761)$ & $-0.168(-0.109)$ & $0.836(0.821)$ & $\approx 1$ \\
\hline$R M S E_{Q_{l F r}}\left(m^{3} \cdot s^{-1}\right)$ & $1919(2090)$ & $1925(2098)$ & $4563(4521)$ & $1712(1815)$ & $8.419(8.123)$ \\
\hline$N R M S E_{Q_{l F r}}$ & $12.13 \%(13.52 \%)$ & $12.17 \%(13.58 \%)$ & $28.84 \%(29.25 \%)$ & $10.82 \%(11.74 \%)$ & $0.053 \%(0.053 \%)$ \\
\hline$R M S N E_{Q_{l F r}}$ & $12.46 \%(15.07 \%)$ & $12.5 \%(15.13 \%)$ & $23.11 \%(24.34 \%)$ & $11.67 \%(13.28 \%)$ & $0.05 \%(0.049 \%)$ \\
\hline
\end{tabular}

Table 7 - Coefficients and efficiency criteria (see Sec. A) on both the calibration and validation (in parenthesis) time window for SFD and low Froude laws for the virtual station downstream of the Rio Negro $(x=779 \mathrm{~km})$.

\section{AMHG}

Hydraulic geometries from Leopold and Madock (1956) writes as:

$$
\left\{\begin{array}{c}
W=a Q^{b_{h g}} \\
h=c Q^{d} \\
U=e Q^{f}
\end{array}\right.
$$

with $a, b_{h g}, c, d, e, f$ being positive constants. As remarked by Leopold and Maddock [1953] and by definition of discharge (for a rectangular cross-section) $Q=W h U$ the combination of the three above equations gives ace $=1$ and $b_{h g}+d+f=1$. This study also highlights that "similar variations in relation to discharge exist in length of a river under the condition that discharge at all points is equal in frequency of occurrence". Using a log linearization of those hydraulic geometries gives the AMHG relationships (see [Gleason and Smith, 2014], PNAS) rewritten here so as to make clearly appear the spatial variability:

$$
\left\{\begin{array}{c}
\frac{1}{\ln Q(x, t)} \ln (W(x, t))=\frac{1}{\ln Q(x, t)} \ln (a(x))+b_{h g}(x) \\
\frac{1}{\ln Q(x, t)} \ln (h(x, t))=\frac{1}{\ln Q(x, t)} \ln (c(x))+d(x) \\
\frac{1}{\ln Q(x, t)} \ln (U(x, t))=\frac{1}{\ln Q(x, t)} \ln (e(x))+f(x)
\end{array} \quad \forall x, \forall t,\right.
$$




\section{Usual parameterizations of flow resistance}

The discharge of gradually varied flows can be locally (at a cross-section) related to the friction slope and the flow parameters can be empirically parametrized by any product of flow parameters with the appropriate coefficients. Usual hydraulic friction parameterizations are recalled in the following table (inspired by Rodríguez et al. [2020])

\begin{tabular}{|c|c|c|c|c|c|}
\hline parameter & Manning & Manning Shallow 1 & Manning Shallow 2 & Darcy-Weisbach & Chezy \\
\hline$A$ & 1 & $5 / 3$ & 0 & 0 & 0 \\
\hline$W$ & 0 & $-2 / 3$ & 1 & 0 & 1 \\
\hline$S_{f}$ & 0.5 & 0.5 & 0.5 & 0.5 & 0.5 \\
\hline$R_{h}$ & $2 / 3$ & 0 & $5 / 3$ & $5 / 3$ & $3 / 2$ \\
\hline$\rho^{-1}$ & $K$ & $K$ & $K$ & $\sqrt{\frac{\pi^{2} g}{8 f_{D}}}$ & $\frac{\sqrt{g}}{\Omega}$ \\
\hline
\end{tabular}

Table 8 - Usual parameterizations of hydraulic friction: significance and values of parameters $p_{i}$ and exponents $\alpha_{i}$ in general equation (3) adapted from Rodríguez et al. [2020].

with $f_{D}$ the Darcy friction factor, $\Omega$ the Chezy flow resistance

\section{References}

D. E. Alsdorf, E. Rodríguez, and D. P. Lettenmaier. Measuring surface water from space. Reviews of Geophysics, 45(2), 2007. doi: https://doi.org/10.1029/2006RG000197. URL https://agupubs . onlinelibrary · wiley . com/ doi/abs/10.1029/2006RG000197.

J. A. Andriambeloson, A. Paris, S. Calmant, and S. Rakotondraompiana. Re-initiating depth-discharge monitoring in small-sized ungauged watersheds by combining remote sensing and hydrological modelling: a case study in madagascar. Hydrological Sciences Journal, 65(16):2709-2728, nov 2020. doi: 10.1080/02626667.2020.1833013.

S. Biancamaria, M. Durand, K. M. Andreadis, P. D. Bates, A. Boone, N. M. Mognard, E. Rodriguez, D. E. Alsdorf, D. P. Lettenmaier, and E. A. Clark. Assimilation of virtual wide swath altimetry to improve arctic river modeling. Remote Sensing of Environment, 115(2):373-381, 2011.

S. Biancamaria, D. P. Lettenmaier, and T. M. Pavelsky. The swot mission and its capabilities for land hydrology. Surveys in Geophysics, 37(2):307-337, 2016.

S. J. Birkinshaw, G. M. O'donnell, P. Moore, C. G. Kilsby, H. J. Fowler, and P. A. M. Berry. Using satellite altimetry data to augment flow estimation techniques on the mekong river. Hydrological Processes, 24(26):3811-3825, 2010.

D. M. Bjerklie, S. L. Dingman, C. J. Vorosmarty, C. H. Bolster, and R. G. Congalton. Evaluating the potential for measuring river discharge from space. Journal of Hydrology, 278(1-4):17-38, 2003.

D. M. Bjerklie, S. L. Dingman, and C. H. Bolster. Comparison of constitutive flow resistance equations based on the manning and chezy equations applied to natural rivers. Water Resources Research, 41(11), 2005.

S. Bogning, F. Frappart, A. Paris, F. Blarel, F. Niño, S. Saux Picart, P. Lanet, F. Seyler, G. Mahé, R. Onguene, J.-P. Bricquet, J. Etame, M.-C. Paiz, and J.-J. Braun. Hydro-climatology study of the ogooué river basin using hydrological modeling and satellite altimetry. Advances in Space Research, apr 2020. doi: 10.1016/j.asr.2020.03. 045. 
J. Brêda, R. Paiva, J. M. Bravo, O. A. Passaia, and D. M. Moreira. Assimilation of satellite altimetry data for effective river bathymetry. Water Resources Research, 55(9):7441-7463, 2019.

P. Brisset, J. Monnier, P.-A. Garambois, and H. Roux. On the assimilation of altimetric data in 1d saint-venant river flow models. Adv. Water Ress., 119:41-59, 2018.

D. G. Cacuci, I. M. Navon, and M. Ionescu-Bujor. Computational methods for data evaluation and assimilation. CRC press, 2013.

V. T. Chow. Handbook of applied hydrology. McGraw-Hill Book Co., New-York, 1467 pages, 1964.

W. Collischonn, D. Allasia, B. C. Da Silva, and C. E. M. Tucci. The mgb-iph model for large-scale rainfall—runoff modelling. Hydrological Sciences Journal, 52(5):878-895, 2007. doi: https://doi.org/10.1623/hysj.52.5.878.

J.-F. Cretaux, K. Nielsen, F. Frappart, F. Papa, S. Calmant, and J. Benveniste. Hydrological applications of satellite altimetry rivers, lakes, man-made reservoirs, inundated areas. In Satellite Altimetry Over Oceans and Land Surfaces, pages 459-504. CRC Press, 2017.

J. Cunge. Practical aspects of computational river hydraulics. Pitman Publishing Ltd. London,(17 CUN), 1980, 420, 1980.

P. R. Dhote, P. K. Thakur, A. Domeneghetti, A. Chouksey, V. Garg, S.P. Aggarwal, and P. Chauhan. The use of saral/altika altimeter measurements for multi-site hydrodynamic model validation and rating curves estimation: An application to brahmaputra river. Advances in Space Research, 2020. ISSN 0273-1177. doi: https://doi.org/10. 1016/j.asr.2020.05.012. URL https://www.sciencedirect.com/science/article/pii/S0273117720303355.

S. L. Dingman. Fluvial hydraulics. oxford university press, 2009.

M. Durand, L.-L. Fu, D. P. Lettenmaier, D. E. Alsdorf, E. Rodriguez, and D. Esteban-Fernandez. The surface water and ocean topography mission: Observing terrestrial surface water and oceanic submesoscale eddies. Proceedings of the IEEE, 98(5):766-779, 2010.

M. Durand, J. Neal, E. Rodríguez, K. M. Andreadis, L. C. Smith, and Y. Yoon. Estimating reach-averaged discharge for the river severn from measurements of river water surface elevation and slope. Journal of Hydrology, 511: 92-104, 2014.

C. M. Emery, A. Paris, S. Biancamaria, A. Boone, S. Calmant, P.-A. Garambois, and J. Santos Da Silva. Largescale hydrological model river storage and discharge correction using a satellite altimetry-based discharge product. Hydrology and Earth System Sciences, 22(4):2135-2162, 2018.

C. M. Emery, A. Paris, S. Biancamaria, A. Boone, S. Calmant, P.-A. Garambois, J. Da Silva, and C. H. David. Discharge estimation via assimilation of multisatellite-based discharge products: Case study over the amazon basin. IEEE Geoscience and Remote Sensing Letters, 2020.

B. M. Fekete and C. J. Vörösmarty. The current status of global river discharge monitoring and potential new technologies complementing traditional discharge measurements. IAHS publ, 309:129-136, 2007.

A. S. Fleischmann, R. C. D. Paiva, W. Collischonn, V. A. Siqueira, A. Paris, D. M. Moreira, F. Papa, A. A. Bitar, M. Parrens, F. Aires, et al. Trade-offs between 1-d and 2-d regional river hydrodynamic models. Water Resources Research, 56(8):e2019WR026812, 2020. 
P-A. Garambois and J. Monnier. Inference of effective river properties from remotely sensed observations of water surface. Advances in Water Resources, 79:103-120, 2015.

P.-A. Garambois, S. Calmant, H. Roux, A. Paris, J. Monnier, P. Finaud-Guyot, A. Montazem, and J. Santos Da Silva. Hydraulic visibility: Using satellite altimetry to parameterize a hydraulic model of an ungauged reach of a braided river. Hydro. Proc., 2017.

P-A Garambois, K. Larnier, J. Monnier, P. Finaud-Guyot, J. Verley, A. Montazem, and S. Calmant. Variational estimation of effective channel and ungauged anabranching river discharge from multi-satellite water heights of different spatial sparsity. Journal of Hydrology, 581:124409, 2020a.

P-A. Garambois, K. Larnier, J. Monnier, P. Finaud-Guyot, J. Verley, A. Montazem, and Calmant S. Variational inference of effective channel and ungauged anabranching river discharge from multi-satellite water heights of different spatial sparsity. Journal of Hydrology, 2020b.

A. Gelman, J. B. Carlin, H. S. Stern, D. B. Dunson, A. Vehtari, and D. B. Rubin. Bayesian data analysis. CRC press, 2013.

A. C. V. Getirana and C. Peters-Lidard. Estimating water discharge from large radar altimetry datasets. Hydrology \& Earth System Sciences, 17(3), 2013.

935 J.-C. Gilbert and C. Lemaréchal. Some numerical experiments with variable storage quasi-newton algorithms. Mathematical Programming, 45:407-435, 08 1989. doi: https://doi.org/10.1007/BF01589113.

C. J. Gleason and L. C. Smith. Toward global mapping of river discharge using satellite images and at-many-stations hydraulic geometry. Proceedings of the National Academy of Sciences, 111(13):4788-4791, 2014. ISSN 0027-8424. doi: 10.1073/pnas.1317606111. URL https ://www.pnas.org/content/111/13/4788.

L. Hascoet and V. Pascual. The tapenade automatic differentiation tool: Principles, model, and specification. 39 (3), 2013. ISSN 0098-3500. doi: https://doi.org/10.1145/2450153.2450158.

C. Kittel, L. Jiang, C. Tottrup, and P. Bauer-Gottwein. Sentinel-3 radar altimetry for river monitoring-a catchmentscale evaluation of satellite water surface elevation from sentinel-3a and sentinel-3b. Hydrology and Earth System Sciences, 25(1):333-357, 2021.

K. Larnier and J. Monnier. Hybrid neural network - variational data assimilation algorithm to infer river discharges from swot-like data. Nonlinear Processes in Geophysics Discussions, 2020:1-30, 2020. doi: https://doi.org/10. 1016/10.5194/npg-2020-32.

K. Larnier, J. Monnier, P.-A. Garambois, and J. Verley. River discharge and bathymetry estimations from SWOT altimetry measurements. Inverse Problems Sc. Eng., 2020. URL https://hal.archives-ouvertes. fr/hal-01811683.

E. M. Latrubesse and E. Franzinelli. The late quaternary evolution of the negro river, amazon, brazil: implications for island and floodplain formation in large anabranching tropical systems. Geomorphology, 70(3-4):372-397, 2005 .

J. Le Coz, B. Renard, L. Bonnifait, F. Branger, and R. Le Boursicaud. Combining hydraulic knowledge and uncertain gaugings in the estimation of hydrometric rating curves: A bayesian approach. Journal of Hydrology, 509:573-587, 2014. 
J. G. Leon, S. Calmant, F. Seyler, M.-P. Bonnet, M. Cauhopé, F. Frappart, N. Filizola, and P. Fraizy. Rating curves and estimation of average water depth at the upper negro river based on satellite altimeter data and modeled discharges. Journal of hydrology, 328(3-4):481-496, 2006.

L. B. Leopold and T. Maddock. The hydraulic geometry of stream channels and some physiographic implications, volume 252. US Government Printing Office, 1953.

V. Mansanarez, J. Le Coz, B. Renard, M. Lang, G. Pierrefeu, and P. Vauchel. Bayesian analysis of stage-falldischarge rating curves and their uncertainties. Water Resources Research, 52(9):7424-7443, 2016. doi: 10.1002/ 2016WR018916. URL https://agupubs.onlinelibrary.wiley.com/doi/abs/10.1002/2016WR018916.

V. Mansanarez, I. K. Westerberg, N. Lam, and S. W. Lyon. Rapid stage-discharge rating curve assessment using hydraulic modeling in an uncertainty framework. Water Resources Research, 55(11):9765-9787, 2019. doi: https://doi.org/10.1029/2018WR024176. URL https://agupubs.onlinelibrary.wiley.com/doi/abs/ 10.1029/2018WR024176.

J. Monnier and K. et al. Larnier. Dassflow: Data assimilation for free surface flows. open-source computational software. Technical report, Mathematics Institute of Toulouse - INSA - CNES - CNRS, 2018. URL http: //www.math.univ-toulouse.fr/DassFlow.

J. Monnier, F. Couderc, D. Dartus, K. Larnier, R. Madec, and J-P. Vila. Inverse algorithms for 2D shallow water equations in presence of wet dry fronts. application to flood plain dynamics. Advances in Water Resources, 97: 11-24, 2016. doi: https://doi.org/10.1016/j.advwatres.2016.07.005.

A. Montazem, P-A. Garambois, S. Calmant, P. Finaud-Guyot, J. Monnier, D. Medeiros Moreira, J. T. Minear, and S. Biancamaria. Wavelet-based river segmentation using hydraulic control-preserving water surface elevation profile properties. Geophysical Research Letters, 46(12):6534-6543, 2019. doi: 10.1029/2019GL082986. URL https://agupubs .onlinelibrary.wiley.com/doi/abs/10.1029/2019GL082986.

F. E. O'Loughlin, J. Neal, D. Yamazaki, and P. D. Bates. Icesat-derived inland water surface spot heights. Water Resources Research, 52(4):3276-3284, 2016.

F. E. O'Loughlin, J. Neal, G. J. P. Schumann, E. Beighley, and P. D. Bates. A lisflood-fp hydraulic model of the middle reach of the congo. Journal of Hydrology, 580:124203, 2020.

H. Oubanas, I. Gejadze, P.-O. Malaterre, M. Durand, R. Wei, R. Frasson, and A. Domeneghetti. Discharge estimation in ungauged basins through variational data assimilation: The potential of the swot mission. Water Resources Research, 54(3):2405-2423, 2018.

D. Paiva, W. Collischonn, M.-P. Bonnet, F. Frappart, S. Calmant, and C. Bulhques Mendes. Large-scale hydrologic and hydrodynamic modeling of the amazon river basin. Water Resources Research, 49(3):1226-1243, 2013a.

R. C. D. Paiva, W. Collischonn, M.-P. Bonnet, L. G. G. De Goncalves, S. Calmant, A. Getirana, and J. S. Da Silva. Assimilating in situ and radar altimetry data into a large-scale hydrologic-hydrodynamic model for streamflow forecast in the amazon. 2013b.

A. Paris, R. Dias de Paiva, J. Santos Da Silva, D. Medeiros Moreira, S. Calmant, P.-A. Garambois, W. Collischonn, M.-P. Bonnet, and F. Seyler. Stage-discharge rating curves based on satellite altimetry and modeled discharge in the amazon basin. Water Resources Research, 2016. 
A. Paris, S. Calmant, M. Gosset, A. Fleischmann, T. Conchy, J.-P. Bricquet, P.-A. Garambois, F. Papa, R. Tshimanga, G. Gulemvuga Guzanga, and et al. Monitoring hydrological variables from remote sensing and modelling in the congo river basin. Earth and Space Science Open Archive, page 53, 2020. doi: 10.1002/essoar.10505518.1. URL https://doi.org/10.1002/essoar.10505518.1.

J.-F. Pekel, A. Cottam, N. Gorelick, and A. S. Belward. High-resolution mapping of global surface water and its long-term changes. Nature, 540(7633):418-422, 2016.

P. R. M. Pontes, F. M. Fan, A. S. Fleischmann, R. Paiva, D. C. Buarque, V. A. Siqueira, P. F. Jardim, M. V. Sorribas, and W. Collischonn. MGB-IPH model for hydrological and hydraulic simulation of large floodplain river systems coupled with open source GIS. Environmental Modelling \&5 Software, 94:1-20, aug 2017. doi: 10.1016/j.envsoft.2017.03.029.

L. Pujol, P.-A. Garambois, P. Finaud-Guyot, J. Monnier, K. Larnier, R. Mosé, S. Biancamaria, H. Yésou, D. Moreira, A. Paris, and S. Calmant. Estimation of multiple inflows and effective channel by assimilation of multi-satellite hydraulic signatures: The ungauged anabranching negro river. Journal of Hydrology, 2020. doi: https://doi.org/ 10.1016/j.jhydrol.2020.125331.

M. Ricko, J. A. Carton, C. M. Birkett, and J.-F. Crétaux. Intercomparison and validation of continental water level products derived from satellite radar altimetry. Journal of Applied Remote Sensing, 6(1):061710, 2012.

E. Rodríguez, M. Durand, and R. Frasson. Observing rivers with varying spatial scales. Water Resources Research, 56(9):e2019WR026476, 2020. doi: https://doi.org/10.1029/2019WR026476. URL https://agupubs. onlinelibrary.wiley.com/doi/abs/10.1029/2019WR026476. e2019WR026476 10.1029/2019WR026476.

E. Rodriguez, D. Esteban Fernandez, E. Peral, C. W. Chen, J.-W. De Bleser, and B. Williams. Wide-swath altimetry: a review. Satellite altimetry over oceans and land surfaces, 2, 2018.

E. Rodríguez et al. Swot science requirements document. JPL document, JPL, 2012.

R. Schneider, M.-E. Ridler, P. N. Godiksen, H. Madsen, and P. Bauer-Gottwein. A data assimilation system combining cryosat-2 data and hydrodynamic river models. Journal of Hydrology, 557:197-210, 2018.

C. Schwatke, D. Dettmering, W. Bosch, and F. Seitz. Dahiti-an innovative approach for estimating water level time series over inland waters using multi-mission satellite altimetry. Hydrology and Earth System Sciences 19 (10): 4345-4364, 2015.

J. S. Da Silva, S. Calmant, F. Seyler, O. C. R. Filho, G. Cochonneau, and W. J. Mansur. Water levels in the amazon basin derived from the ERS 2 and ENVISAT radar altimetry missions. Remote Sensing of Environment, 114(10):2160-2181, oct 2010. doi: 10.1016/j.rse.2010.04.020.

L. C. Smith, B. L. Isacks, A. L. Bloom, and A. B. Murray. Estimation of discharge from three braided rivers using synthetic aperture radar satellite imagery: Potential application to ungaged basins. Water Resources Research, 32(7):2021-2034, 1996.

S. Tuozzolo, G. Lind, B. Overstreet, J. Mangano, M. Fonstad, M. Hagemann, R. Frasson, K. Larnier, P.-A. Garambois, J. Monnier, et al. Estimating river discharge with swath altimetry: A proof of concept using airswot observations. Geophysical Research Letters, 46(3):1459-1466, 2019.

S. Wongchuig-Correa, R. C. D. de Paiva, S. Biancamaria, and W. Collischonn. Assimilation of future swot-based river elevations, surface extent observations and discharge estimations into uncertain global hydrological models. Journal of Hydrology, 590:125473, 2020. 
H. J. Zwally, R. Schutz, C. Bentley, J. Bufton, T. Herring, J. Minster, J. Spinhirne, and R. Thomas. Glas/icesat 12 antarctic and greenland ice sheet altimetry data v031, boulder, colorado: Nasa distributed active archive center at the national snow and ice data center. Digital media, 2012. 